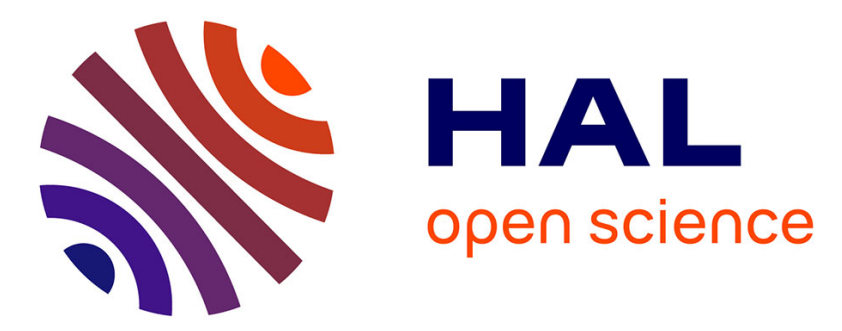

\title{
An overview of the thermal erasure mechanisms of femtosecond laser induced nanogratings in silica glass
}

Yitao Wang, Maxime Cavillon, Nadège Ollier, Bertrand Poumellec, Matthieu Lancry

\section{- To cite this version:}

Yitao Wang, Maxime Cavillon, Nadège Ollier, Bertrand Poumellec, Matthieu Lancry. An overview of the thermal erasure mechanisms of femtosecond laser induced nanogratings in silica glass. physica status solidi (a), 2021, 218, pp.2100023. 10.1002/pssa.202100023 . hal-03418493

\section{HAL Id: hal-03418493 \\ https://hal.science/hal-03418493}

Submitted on 7 Nov 2021

HAL is a multi-disciplinary open access archive for the deposit and dissemination of scientific research documents, whether they are published or not. The documents may come from teaching and research institutions in France or abroad, or from public or private research centers.
L'archive ouverte pluridisciplinaire $\mathbf{H A L}$, est destinée au dépôt et à la diffusion de documents scientifiques de niveau recherche, publiés ou non, émanant des établissements d'enseignement et de recherche français ou étrangers, des laboratoires publics ou privés. 


\title{
An overview of the thermal erasure mechanisms of femtosecond laser induced nanogratings in silica glass
}

Yitao Wang, Maxime Cavillon, Nadège Ollier, Bertrand Poumellec, and Matthieu Lancry*

Mr. Wang, Dr. Cavillon, Prof. Poumellec, Dr. Lancry

Institut de Chimie Moléculaire et des Matériaux d'Orsay (ICMMO/SP2M/MAP), Université Paris-Saclay, CNRS, 91405 Orsay Cedex, France

E-mail : matthieu.lancry@universite-paris-saclay.fr

Dr. Nadège Ollier

LSI, CEA/DRF/lRAMIS, Ecole Polytechnique, CNRS, Institut Polytechnique de Paris, 91128 Palaiseau, France

Keywords: nanogratings, birefringence, femtosecond laser, silica glass

\begin{abstract}
The Type II modifications induced by IR femtosecond (fs) laser are used in many optical devices due to their excellent thermal stability at high temperatures (typically> $800{ }^{\circ} \mathrm{C}$ ). The characteristic feature of Type II modifications is the formation of nanogratings, which can easily be detected through birefringence measurements. However, the measured birefringence is an aggregate value of multiple contributions that include form birefringence, stress-induced birefringence due to permanent volume changes, and point defects. In this work, we investigate the thermal erasure kinetics for each one of these contributions in silica glass. Firstly, we irradiate silica glass samples with a fs-laser using different conditions (polarization, energy). Secondly, we perform accelerated aging experiments to evaluate the stability of the laser-induced modifications, including defects, densification, stress field and porous nanogratings. Finally, the aforementioned contributions to the thermal stability of the nanogratings are identified and discussed using spectroscopic techniques (Raman and Rayleigh scattering, UV-Vis absorption) and electron microscopy. Moreover, porous nanogratings erasure kinetic is simulated using the Rayleigh-Plesset (R-P) equation. This work provides a valuable framework in the realization of silica glass-based optical devices operating at high temperatures $\left(>>800{ }^{\circ} \mathrm{C}\right)$ by 1$)$ evidencing the effect of annealing on each erasure mechanism and 2) providing information on the optical response (mainly the birefringence) upon annealing.
\end{abstract}

\section{Introduction}

Over the past two decades, significant progress has been made to identify different types of material modifications occurring upon Infrared (IR) or Visible (Vis) femtosecond laser (fs-laser) light focused inside transparent dielectrics ${ }^{[1]}$. Femtosecond light pulses, with laser fluence above the multiphoton ionization threshold, can deposit their energy homogeneously and in volume in transparent dielectrics producing moderate density plasmas ${ }^{[2]}$. In 1999, anomalous anisotropic scattering of light ${ }^{[3]}$ in Ge-doped silica glass was observed, and then the memorized polarization-dependent light scattering ${ }^{[4]}$ was reported in 2000. Following this, in 2001 there was the first experimental observation of strong linear 


\section{WILEY-VCH}

birefringence $^{[5]}$ in fused silica from fs-modified zones. These works provided the first clues of nanogratings formation in the glass volume. The first direct evidence for periodic nanogratings came in 2003 using a stationary and fixed focus fs-laser beam ${ }^{[6]}$. Later our group revealed that these self-organized subwavelength nanolayers are based on glass decomposition that resolidifies into a nanoporous, usually silicon-rich structure, creating a strong and highly stable refractive index contrast ${ }^{[7]}$. Since then, studies have been conducted to improve the control of nanogratings fabrication, leading to many novel applications mostly based on birefringent devices. For example, the fabrication of these nanogratings have found applications for 2D- and 3D-based space variant birefringence objects (such as waveplates ${ }^{[8]}$, micro-patterned waveplates, polarization converters), high temperature Fiber Bragg Gratings (FBG) ${ }^{[9]}$ for Structural Health Monitoring (SHM), or again 5D optical data storage ${ }^{[10,11]}$ with virtually "unlimited lifetime" at room temperature. For most of these optical devices, the thermal stability is an important factor to be considered to ensure a reliable functionality during their lifetime, e.g., to prevent any drift in the device optical response over time. Therefore, the study on the thermal stability of the fs-Type II modifications (i.e. nanogratings regime) is of great significance to understand the mechanisms of erasure before to be able to perform a reliable lifetime prediction.

In 2006, Bricchi et al. ${ }^{[12]}$ reported the first results related to the annealing of fs-laser written type II modifications (Laser conditions: $\lambda=800 \mathrm{~nm}, 100 \mathrm{kHz}, \mathrm{NA}=0.55,0.06 \mathrm{~mm} / \mathrm{s}$, pulse duration $=200 \mathrm{fs}$ ), which showed extraordinary thermal stability: such modifications can withstand at least 2 hours at $1000{ }^{\circ} \mathrm{C}$ without any degradation. The unexpected behavior displayed by these structures, namely a slight growth of the absolute value of the ordinary and extraordinary refractive index difference as the temperature progressively increased in the 200-500 ${ }^{\circ} \mathrm{C}$ range, was suggested to come from the erasure of point defects centers like $\mathrm{SiODC}$ and $\mathrm{SiE}$ ' defects generated in the irradiated volume.

This was followed by a few studies as summarized here. In 2012, Richter et al. ${ }^{\text {[13] }}$ confirmed that nanogratings exhibit an extremely high temperature stability, i.e., up to $1150{ }^{\circ} \mathrm{C}$ for 30 minutes (Laser conditions: $\lambda=1030-515 \mathrm{~nm}, 9.4 \mathrm{MHz}$, average power $=5 \mathrm{~W}$, $\mathrm{NA}=0.55$, pulse duration $=450 \mathrm{fs}$ ). Investigations of the thermal stability of nanogratings showed that $\mathrm{E}^{\prime}$ centers vanished upon annealing, whereas NBOHCs remained stable up to $900{ }^{\circ} \mathrm{C}$ for $2 \mathrm{~h}$. Thus, they proposed that nanogratings based components could be rendered truly thermally stable by a thermal annealing in order to erase the unstable part mostly related to point defects.

Krol et al. ${ }^{[14]}$ have subsequently investigated the thermal stability of femtosecond laser modification inside fused silica (Laser conditions: $\lambda=800 \mathrm{~nm}, 1 \mathrm{kHz}, \mathrm{NA}=0.25,0.05$ $\mathrm{mm} / \mathrm{s}$, pulse duration $=150 \mathrm{fs}$ ). Raman and photo-luminescence spectroscopy showed that fslaser induced non-bridging oxygen hole center (NBOHC) defects completely disappeared at $300{ }^{\circ} \mathrm{C}$ (for a 10 hours annealing), whereas changes in Si-O ring structures only annealed out after heat treatment at $800-900{ }^{\circ} \mathrm{C}$ (for a 10 hours annealing). After an annealing at $900{ }^{\circ} \mathrm{C}$ for 10 hours, optical waveguides written inside the glass had completely disappeared whereas more significant damages induced in the glass remained.

In 2014, Zhang et al. ${ }^{[15]}$ highlighted that the linear birefringence response of the nanogratings experiences a slight increase with increasing annealing temperature up to $900{ }^{\circ} \mathrm{C}$ (Laser conditions: $\lambda=800 \mathrm{~nm}, 1 \mathrm{kHz}, \mathrm{NA}=0.55,0.01 \mathrm{~mm} / \mathrm{s}$, pulse energy $=2 \mu \mathrm{J}$, pulse 


\section{WILEY-VCH}

duration $=150 \mathrm{fs}$, laser polarization at $45^{\circ}$ off the writing direction $)$ in agreement with Bricchi et al. ${ }^{[12]}$. But after annealing at $1100{ }^{\circ} \mathrm{C}$ for 1 hour, the birefringence sharply decreased by a factor of 4 . They also monitored the so-called "defects lines" (labeled D1 and D2) using Raman spectroscopy as a function of temperature. These lines are related to 3 and 4-membered rings in the silica network. In this study, the authors found no correlations between the evolution of the lines and the overall birefringence response. Furthermore, in this study the authors also performed Scanning Electron Microscopy (SEM) experiments in which the width of nanoplane period (nanogratings etched by HF acid) decreased from $120 \mathrm{~nm}$ to 50 $\mathrm{nm}$ after an annealing at $1100{ }^{\circ} \mathrm{C}$ for 1 hour; but again they do not reveal any direct correlation with the quantitative birefringence measurements.

Although there are a numerous studies about the thermal stability of optical properties within type II regime, i.e. retardance in bulk samples ${ }^{[10,12,13,15-19]}$ but also Bragg wavelength shift ${ }^{[20]}$ and/or Reflectivity of Fiber Bragg gratings ${ }^{[21-29]}$. However, there are only few studies about the erasure kinetics of the underlying mechanisms supporting these optical properties as we have summarized in the previous paragraphs. In addition, the measured birefringence within nanogratings regime is composed by multiple contributions including the well-known form birefringence but also stress-induced birefringence, point defects, densification. Since these modifications are intrinsically different from each other, they likely present a different thermal behavior as well. Following this view, we propose here a comprehensive overview of these erasure mechanisms, associated to an extensive set of data in silica glass. The strategy is to investigate in details the overall erasure mechanisms of Type II IR fs-laser modifications by comparing the thermal stability of the measured linear retardance to the one of:

- $\quad$ Defect centers (i.e. SiODC(II) and SiE')

- $\quad$ Rayleigh scattering signature

- Densification through Raman micro-spectroscopy,

- $\quad$ Stress-induced birefringence using a dedicated stress-engineered waveplate,

- $\quad$ Nanogratings texturing (period, porosity filling factor, nanopores size).

Additionally, in this work we quantify, within our working conditions, the amplitude that each mechanism has on the "aggregate" measured retardance, and provide some elements about the densification nature within the Type II regime. Lastly, with this paper, we frame under which annealing conditions each one of the aforementioned contributions will be active, and to what extend the optical response, especially retardance or birefringence herein, is expected to change. With this in mind, this work paves the way to complete description of the thermally affected mechanisms that impact glass-based devices under high temperature operation. It will provide guidelines to future glass formulation development and the use of adequate laser parameters depending on priorities (low losses, high temperature operation, high birefringence values, etc.)

\section{Materials and Methods}

Femtosecond laser writing: The experimental setup of the infrared femtosecond laser direct writing procedure is shown in Figure 1 and has been described accurately in previous works ${ }^{[7,8,17]}$. In this study, briefly, the commercial Suprasil ${ }^{\circledR}$ CG glass from Heraeus (a synthetic Type III pure $\mathrm{SiO}_{2}$ glass ${ }^{[30]}$ ) plates of $3 \mathrm{~mm}$ thick have been used for these 


\section{WILEY-VCH}

investigations. Suprasil ${ }^{\circledR}$ CG glass exhibits 400-1000ppm OH concentration, a high Cl content (typ. 2500ppm) and a minor amount of additional impurities (<10ppb).

The laser beam was produced by a femtosecond laser system operating at $\lambda=1030 \mathrm{~nm}$ and delivering 250-300 fs pulses at a repetition rate of $100 \mathrm{kHz}$ with a maximum available power of $10 \mathrm{~W}$. The beam was focused to a depth of $500 \mu \mathrm{m}$ (in glass) below the front face of $3 \mathrm{~mm}$ thick silica glass plates using a 0.16 NA aspheric lens (estimated beam diameter of $4.1 \mu \mathrm{m})$. Based on preliminary experiments ${ }^{[17]}$, the laser energy and the scanning speed were chosen so that the irradiated region falls within the type II regime (typ. $1.75 \mu \mathrm{J} /$ pulse, 0.5 $\mathrm{mm} / \mathrm{s}$ scanning speed) corresponding to the formation of nanogratings in silica glass. In addition, some Type I modifications were written at $0,15 \mu \mathrm{J} /$ pulse for sake of comparison.

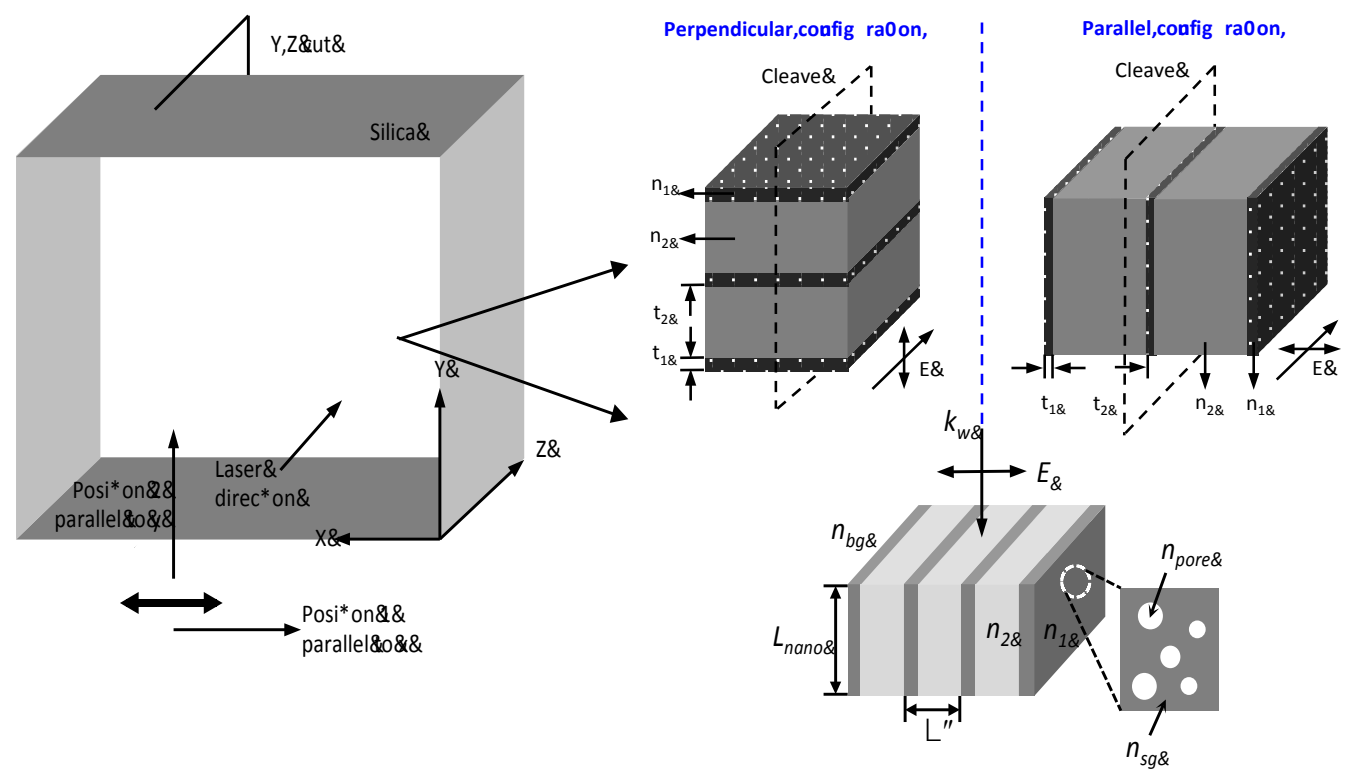

Figure 1. Experimental setup scheme for configuration for writing (from the left to the right top) and schematic of sub-wavelength periodic structure formed in cross-section of the irradiated region. $\mathrm{n}_{1}$ et $\mathrm{n}_{2}$ : local refractive indices of the nanoplates; $t_{1}$ and $t_{2}$, are their respective thicknesses. Bottom right: Schematic of sub-wavelength periodic structure formed in cross-section of the irradiated region. $n_{\text {pore }}$ and $n_{s g}$ : local refractive index of nanopores $\left(n_{\text {pore }}=1\right)$ and for surrounding oxygen defect regions, respectively, $\Lambda=t_{1}+t_{2}$ : period of nanogratings and $\mathrm{n}_{\mathrm{bg}}$ : refractive index of the surrounding material, $\mathrm{L}_{\text {nano }}$ : thickness of nanogratings.

The sample was placed on a XYZ motorized translation stage and the first experiment includes a series of squares $(3 \mathrm{~mm} \times 3 \mathrm{~mm}$ in the $X Y$ plane). The squares are composed of 3000 parallel lines with a $1 \mu \mathrm{m}$ line gap to have a uniform anisotropic area and avoiding any diffraction effects. Note that such a design (array of lines) is representative to various optical components such as polarization converters, waveplates, and waveplates array for polarimetric imaging, stress-engineered waveplates or micro-lenses. The laser beam was scanned along the $\mathrm{X}$-axis and the linear polarization was set at $90^{\circ}$ (i.e., along the $\mathrm{Y}$ axis), $45^{\circ}$, and $22.5^{\circ}$ relative to the scanning direction so we labeled samples Xy, X45 and X22.5.

Accelerated aging: Usually accelerated aging measurements are required to evaluate the stability of nanogratings in their future working conditions. In this work, the decay rate was evaluated using step isochronal annealing experiments in the $100{ }^{\circ} \mathrm{C}$ to $1250{ }^{\circ} \mathrm{C}$ temperature range, and with a fixed step time $(\Delta t=30 \mathrm{~min})$ at each temperature. After the step during which the samples were kept at a temperature for a time $\Delta \mathrm{t}$, the samples were cooled 


\section{WILEY-VCH}

down to room temperature to record the photo-induced birefringence, Raman spectra and the UV-Vis-NIR absorption spectra. Thus, any temperature-induced reversible effects that may occur above room temperature did not spoil the measurements.

Characterization techniques: Optical retardance of the laser-induced modifications, defined as the product of linear birefringence LB by the thickness 1 of the birefringent object i.e., $R=L B \times l$, is measured using an Olympus ${ }^{\circledR} \mathrm{BX} 51$ polarizing optical microscope equipped with a "de Sénarmont" compensator. The "de Sénarmont" compensator couples a high precision quarter waveplate with a 180-degree rotating analyzer to provide retardation measurements in the visible range. Such setup has an accuracy that approaches a few $\mathrm{nm}$ when used in our conditions. Additionally, UV-Vis-NIR absorption spectra were performed using a Cary5000 spectrophotometer in non-polarized light with a data interval of $0.5 \mathrm{~nm}$.

The irradiated zone was also analyzed using Raman micro-spectroscopy in order to track the glass densification signature and to compare it to various silica samples densified under various conditions (thermal, electrons irradiation, High Pressure-High Temperature). Raman spectra were recorded in MONARIS Lab (Paris 6) using a Labram HR microspectrometer (from Horiba Jobin-Yvon) equipped with a $458 \mathrm{~nm}$ Argon laser (6 $\mathrm{mW}$ on the sample) and a x100 microscope objective. All measurements were performed at room temperature.

The second set of experiments was performed to investigate the morphology and the texturing of fs laser-induced glass modifications ${ }^{[31]}$. In this view, two sets of single lines were written using two different laser polarization orientations: parallel (labeled $\mathrm{Xx}$ ) and perpendicular (labeled $\mathrm{Xy}$ ) to the laser scanning direction ( $\mathrm{X}$ axis) and the pulse energy was fixed to $1.2 \mu \mathrm{J} /$ pulse. Then, in order to probe the matter within the nanolayers and its transformation after step isochronal annealing, the sample was cleaved perpendicularly to the writing direction. Such cleaving scheme allowed the laser track cross-sections to be observed by SEM (Field-Emission Gun Scanning Electron Microscope, ZEISS SUPRA 55 VP, 1 kV accelerating voltage) at $1000{ }^{\circ} \mathrm{C}, 1100{ }^{\circ} \mathrm{C}$, and $1200{ }^{\circ} \mathrm{C}$. Depending on the laser polarization orientations along $\mathrm{Xx}$ or $\mathrm{Xy}$, the nanopores can be found in the laser-induced nanoplanes from the former and the nanolayers (sideways visualization of nanoplanes) with a regular spacing would appear in the latter.

\section{Results}

\subsection{Study of the retardance during step isochronal annealing}

Figure 2 displays the retardance $\mathrm{R}_{\text {norm }}(\mathrm{T})$ of the fs-irradiated regions, which is the retardance $(\mathrm{T})$ normalized with respect to the retardance value from the as-irradiated glass at room temperature (RT), as a function of isochronal annealing temperature. Here we selected two kind of irradiated area; namely Type II modifications written at $1.75 \mu \mathrm{J} /$ pulse using different writing configurations and an additional low energy $\left(0.85 \mu \mathrm{J} /\right.$ pulse; $\left.\mathrm{X} 45^{\circ}\right)$ Type II for sake of comparison. Note that the neutral axis did not show any significant rotation during the stage of annealing although the results are characteristic of different decay rates, indicative of distinct erasure mechanisms that will be discussed in the next section. 


\section{WILEY-VCH}

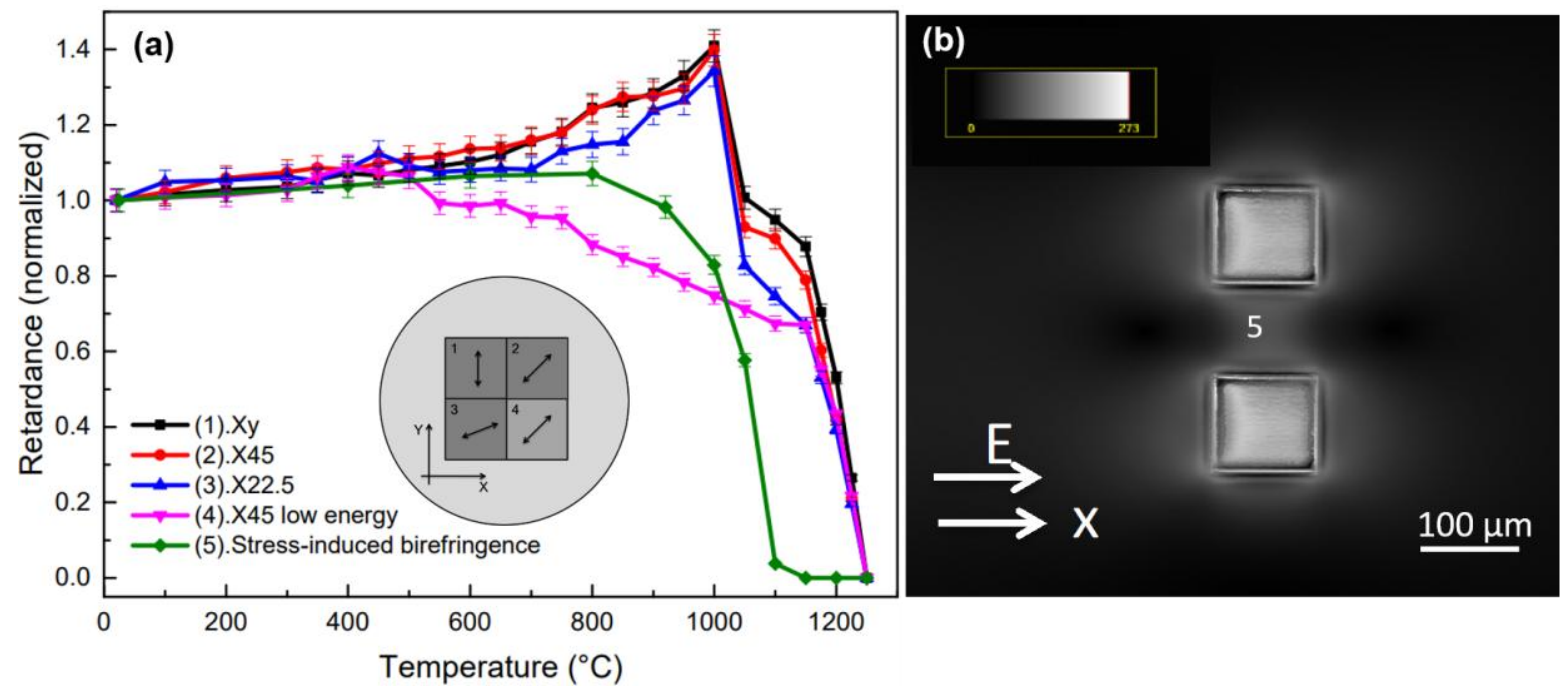

Figure 2. (a): Normalized retardance as a function of temperature using isochronal step $(\Delta t=30 \mathrm{~min})$, and for four "nanogratings" samples, as well as stress-induced birefringence (green curve). The measurements were performed at room temperature (RT). The inset displays the experimental laser writing designs: Four squares (3 $\mathrm{mm} \times 3 \mathrm{~mm}$ ) were written using $\lambda=1030 \mathrm{~nm}, 250-300 \mathrm{fs}, 0,16 \mathrm{NA}, 100 \mathrm{kHz}, 0.5 \mathrm{~mm} / \mathrm{s}, 0.85$ or $1.75 \mu \mathrm{J}$, laser polarization $=22.5^{\circ}, 45^{\circ} 90^{\circ}$. (b): An example of stress-induced birefringence area that could be observed around and between the $0.1 \times 0.1 \mathrm{~mm}^{2}$ squares. The image was taken using an optical microscope with crossed polarizers. The thermal stability of the position marked by " 5 " is also shown (green curve in Figure 2a).

We first focus on the stress-induced birefringence i.e. the green line in Figure $2 \mathrm{a}$. Based on the results published by McMillen et al. ${ }^{[32]}$, the design has been tailored so that we could reach a high optical retardance $R$ of $200 \mathrm{~nm}$ (i.e. a half waveplate at $400 \mathrm{~nm}$ ) within a $0.1 \times 0.1 \mathrm{~mm}^{2}$ area ${ }^{[33]}$ that is free from any laser direct modifications. Here we created twin columns of lines (defined as "stress bar") spaced by $0.1 \mathrm{~mm}$, which defines the clear aperture. Each stress bar is made up of an assembly of 5 layers written with a spacing $\Delta \mathrm{z}$ of $50 \mu \mathrm{m}$. The pulse energy was fixed to $2 \mu \mathrm{J} /$ pulse. In this simple arrangement ${ }^{[32,33]}$, the stress-induced birefringence was detected in-between the two irradiated zone (see Figure 2b), along with a monitoring of its thermal stability and its contribution to the overall retardance. The $R_{\text {norm }}(T)$ of the stress-induced birefringence remained rather stable from RT up to $800{ }^{\circ} \mathrm{C}$. However, beyond $900{ }^{\circ} \mathrm{C}$, its value drastically diminishes, until it reaches zero at $1150{ }^{\circ} \mathrm{C}$ for half an hour $\mathrm{T}$ steps, which is associated to stress relaxation of the silica glass around its glass transition temperature $\mathrm{T}_{\mathrm{g}}{ }^{[34]}$. We note here that the stress field produced by the nanoporous layers does not disappear with the annihilation of the nanopores themselves, which takes place at a higher temperature.

Now, we turn to the evolution of $\mathrm{R}_{\text {norm }}(\mathrm{T})$ values for the other samples shown in Figure 2a. They exhibit a slight increase of $10 \%$ up to $450{ }^{\circ} \mathrm{C}-500{ }^{\circ} \mathrm{C}$, which could be attributed to the erasure of the defects. Then, the modified area corresponding to Type II modifications within low pulse energy $(0.85 \mu \mathrm{J} /$ pulse $)$ declines from $500{ }^{\circ} \mathrm{C}$ to $1150{ }^{\circ} \mathrm{C}$ progressively. However, an opposite trend on the evolution of $\mathrm{R}_{\text {norm }}(\mathrm{T})$ is observed for a higher energy of $1.75 \mu \mathrm{J} /$ pulse in our writing conditions. Indeed, a rather large increase of $\mathrm{R}_{\text {norm }}(\mathrm{T})$ of about $40 \%$ from room temperature up to $1000{ }^{\circ} \mathrm{C}$ is observed. According to the literature it could be related to the co-existence of Type I modifications (defects and densification) within nanogratings ${ }^{[12,23]}$, more details will be given in the end part of the 


\section{WILEY-VCH}

discussion. Above $1000{ }^{\circ} \mathrm{C}, \mathrm{R}_{\text {norm }}(\mathrm{T})$ decreases abruptly and no measurable birefringence can be found after 30 minutes at $1250{ }^{\circ} \mathrm{C}$. It should be pointed out that each irradiated area experiences a different path down to $\mathrm{R}_{\text {norm }}(\mathrm{T})=0$, and more specifically within the $1000{ }^{\circ} \mathrm{C}$ $1100{ }^{\circ} \mathrm{C}$ range where a kind of two-step decay is observed. As discussed above, the stressinduced birefringence was found to rapidly decay in this $1000{ }^{\circ} \mathrm{C}-1100{ }^{\circ} \mathrm{C}$ range. Consequently, we ascribe the observed "first steep decay" of $\mathrm{R}_{\text {norm }}(\mathrm{T})$ from its highest value as a stress relaxation mechanism. The final decay is attributed to the erasure of the nanoporous layers as we modeled recently using Rayleigh-Plesset equation ${ }^{[35]}$. The various observed trends of $\mathrm{R}_{\text {norm }}(\mathrm{T})$, in relationship with different erasure mechanisms, will be investigated in great details in the discussion.

\subsection{Study of point defects stability using UV-Vis absorption spectroscopy}

UV-absorption spectra were collected at room temperature after each annealing step to monitor the absorbance of Type II modifications. The results are reported in Figure 3. Several contributions are aggregated in the absorbance spectra: 1) the intrinsic absorption losses and, 2 ) the light scattering caused by nanostructure ${ }^{[15]}$. As the pristine silica sample, taken as a reference, shows in Figure 3, the non-irradiated glass exhibits a quite flat absorption curve with nearly no absorption from the visible to the near-infrared region. In contrast, the absorbance of Type II modifications significantly increases as one moves along the curve from the visible (Vis) side to the UV side of the spectrum.
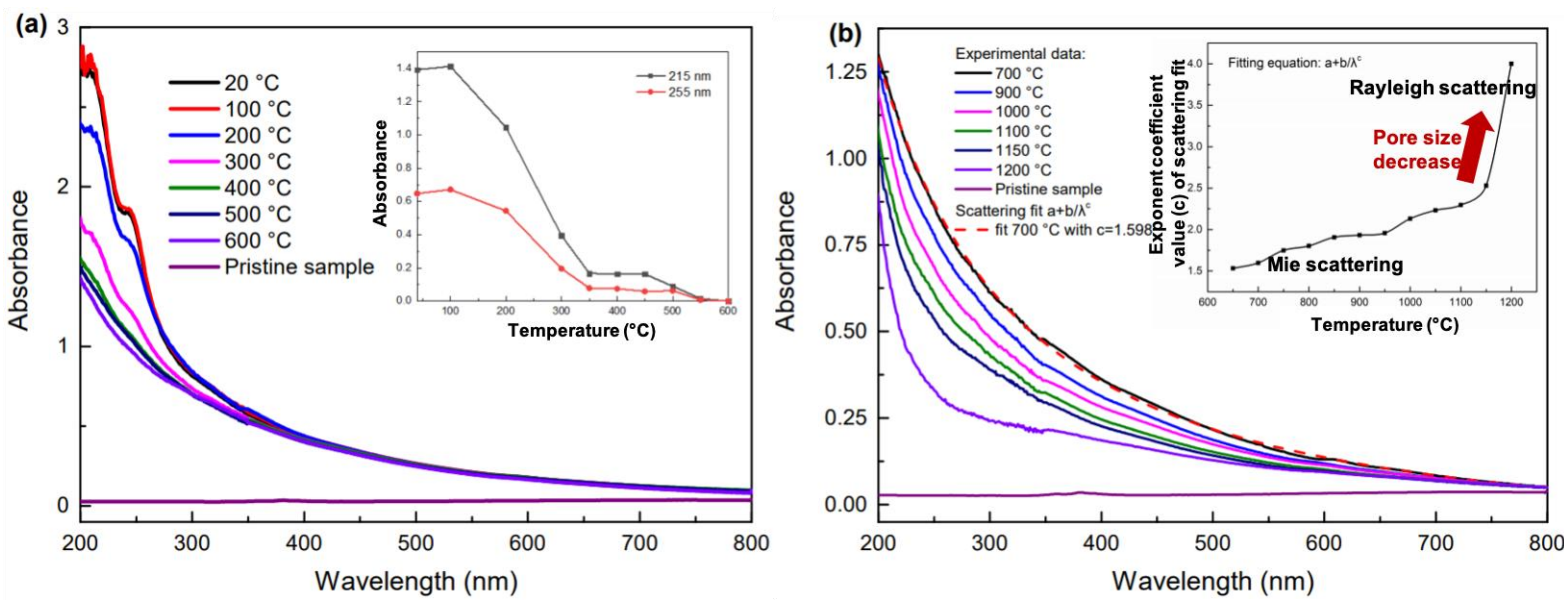

Figure 3. UV-Vis absorption spectra of Type II modification area (square 3 from Figure 2a), as a function of isochronal $(\Delta \mathrm{t}=30 \mathrm{~min})$ annealing temperature: (a) $40{ }^{\circ} \mathrm{C}-600{ }^{\circ} \mathrm{C}$ range and (b) $650{ }^{\circ} \mathrm{C}-1200{ }^{\circ} \mathrm{C}$ range. The spectra of a non-irradiated region (pristine silica) taken at room temperature were added as a reference. In Figure $3 b$ the absorption curve at $700{ }^{\circ} \mathrm{C}$ was fitted by an equation of the form $\mathrm{a}+\mathrm{b} / \lambda^{\mathrm{c}}$, typically relevant to study scattering losses. Inset graph in (a): Absorbance as a function of temperature for the specific wavelengths (215 $\mathrm{nm}$ and $255 \mathrm{~nm}$ ); Inset graph in (b): Exponent coefficient value (c) of the scattering fit and as a function of annealing temperature.

In Figure 3a, the typical band features are clearly annealed away as the temperature is progressively increased from room temperature up to $600{ }^{\circ} \mathrm{C}$. The evolution of these features is attributed to the bleaching of defects. The band peaking at $255 \mathrm{~nm}(5.08 \mathrm{eV})$ corresponds to SiODC(II) whereas the band peaking at $215 \mathrm{~nm}$ (around $5.8 \mathrm{eV}$ ) has been attributed to $\mathrm{SiE}$ ' centers. Upon annealing up to $600{ }^{\circ} \mathrm{C}$ we observe a significant impact on both bands at 5.08 


\section{WILEY-VCH}

$\mathrm{eV}$ and $5.8 \mathrm{eV}$. This is in accordance with the temperature dependent decay of SiE' centers reported by Messina and Cannas ${ }^{[36]}$. After a thermal treatment at $400{ }^{\circ} \mathrm{C}$ most of these defects have been bleached.

For the annealing treatments in the $600-1100{ }^{\circ} \mathrm{C}$ range (see Figure $3 \mathrm{~b}$ ), there is a slight continuous decrease of the UV tail. This "UV tail" is the signature of light scattering and is attributed to the nanoporosity inside the nanoplanes that we have fitted as follows Absorbance $(\lambda, T)=a+b(T) / \lambda^{c(T)}$. The exponent "c(T)" of the fitted equation is increasing from 1.5 (at $600{ }^{\circ} \mathrm{C}$ ) up to 2.5 (at $1100{ }^{\circ} \mathrm{C}$ ) indicating a Mie scattering regime. However, for temperature higher than $1100{ }^{\circ} \mathrm{C}$, the exponent "c" exhibits a steep increase up to the value of 4 , revealing a Rayleigh scattering regime and indicating a decrease of the nanopores size. The " $\mathrm{b}(\mathrm{T})$ " coefficient decreases with $\mathrm{T}$ indicating a decrease of the nanopores filling factor in agreement with the SEM observations. In addition, the polarization dependence of scattered light ${ }^{[37]}$ reveals higher losses for a probe polarization oriented perpendicular to the nanolayers, which indicates that the scattering centers might be inside the nanogratings. This agrees with a layered medium made of alternating layers of two different isotropic materials with complex refractive indices, exhibiting a linear dichroism ${ }^{[38]}$, or more accurately here some polarization dependent scattering losses due to the intrinsic nanoporous nature of the nanogratings ${ }^{[7]}$.

\subsection{Study of densification stability using Micro-Raman spectroscopy}

In this paragraph, we analyze the densification of fs-irradiated silica within type II regime. The principal Raman features of silica glass, peaking at $\sim 40 \mathrm{~cm}^{-1}, 490 \mathrm{~cm}^{-1}$ (D1) and $606 \mathrm{~cm}^{-1}$ (D2), are well observed. The D1 and D2 peaks, attributed to four-member and threemember siloxane rings respectively, are generally (but not always ${ }^{[39]}$ ) characteristics of a "dense" silica glass, and the latter is monitored as a function of temperature as displayed in Figure 4a. The magnitude of the D2 peak intensity is increased for the irradiated samples with respect to the pristine glass. This phenomenon could be attributed to some changes in ring statistics where the dominant five and six-fold rings were transformed by the laser irradiation to three-fold and four-fold rings. This transformation would have the effect of a reduction of the average Si-O-Si bond angle distribution, and would eventually lead to an increase in the glass density ${ }^{[40]}$ in agreement with the shift and the width reduction of the main band at 440 $\mathrm{cm}^{-1}$.

In Figure 4a, as the annealing temperature increases (and this for various conditions), the strength of the D2 line with different laser parameters, previously normalized with respect to the value of the irradiated samples at room temperature (the D2 strength of the pristine sample was taken as zero here), decreases beyond $500{ }^{\circ} \mathrm{C}-600{ }^{\circ} \mathrm{C}$. This reduction could be interpreted by the fact that the densified silica network starts to relax at this range of temperature. Through further observation, according to the different annealing time and laser parameters, the intensity went back to zero around $1000{ }^{\circ} \mathrm{C}-1200{ }^{\circ} \mathrm{C}$. As a side note, the thermal stability of Type II modifications, being function of the laser writing conditions, may explain the subtle differences between each curve ${ }^{[16]}$. 


\section{WILEY-VCH}
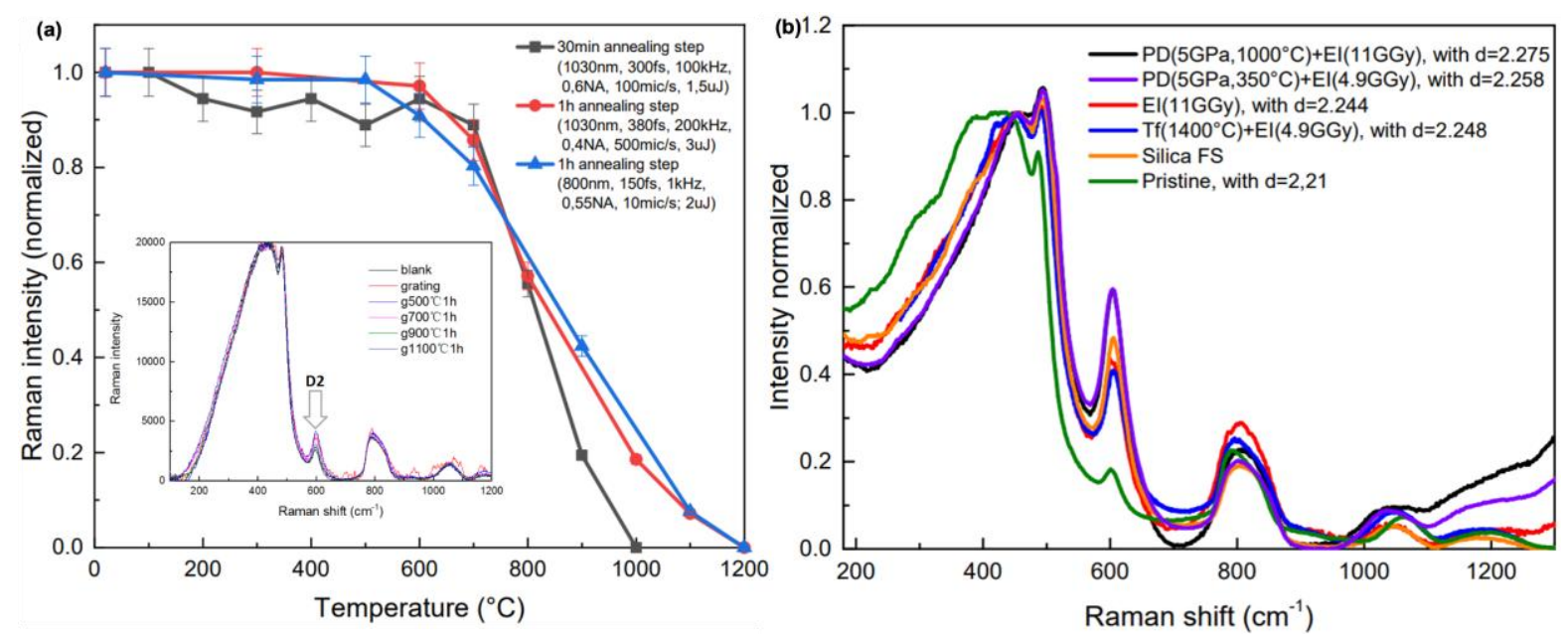

Figure 4. (a): Raman spectra and the evolution as a function of temperature of D2 peak intensity for fs-laser irradiated silica glass. The data extracted from the literature for different annealing times (red: ${ }^{[41]}$, blue: ${ }^{[15]}$ ) are also inserted for comparison. Inset graph: Raman spectra of the area before and after laser irradiation and subsequent annealing during 1 hour ${ }^{[41]}$. (b): Raman spectra of silica with following conditions: black, predensified (PD), $\left(5 \mathrm{GPa}, 100{ }^{\circ} \mathrm{C}\right)+$ electron irradiation (EI), (11 GGy); purple, pre-densified $\left(5 \mathrm{GPa}, 350{ }^{\circ} \mathrm{C}\right)+$ electron irradiation (4.9 GGy); red, electron irradiation (11 GGy); blue, fictive temperature treated $\left(1400{ }^{\circ} \mathrm{C}\right)+$ electron irradiation ( $4.9 \mathrm{GGy})$; the data are extracted from the literature ${ }^{[39,42]}$. Silica irradiated by Femtosecond laser (orange) and the pristine sample (green) are also added for comparison.

In the following, we compare the Raman signature of fs-Type II to the one of various silica samples studied in Refs. ${ }^{[39,42]}$, and for which we have measured their macroscopic density. More specifically, Figure $4 \mathrm{~b}$ shows the Raman spectra of fs-Type II in comparison to high-energy electron irradiated pre-densified silica glasses obtained either from High Pressure-High Temperature (HP-HT) or from thermal treatment increasing their initial fictive temperature $\left(\mathrm{T}_{\mathrm{f}}{ }^{[39]}\right.$. From there, we can see that the Raman signature of fs-Type II mimics the one of HP-HT or high $\mathrm{T}_{\mathrm{f}}$ samples that have been irradiated to high electron dose (5-11 GGy range). In particular Raman spectrum of fs-Type II silica is quite close to both $\mathrm{T}_{\mathrm{f}}$ $1400{ }^{\circ} \mathrm{C}$ silica irradiated at $5 \mathrm{GGy}$, and sample irradiated at $11 \mathrm{GGy}$. The densities of latter samples are 2.248 and 2.244, respectively. This further confirms that the material between porous layers exhibits similar characteristics as Type I modification i.e. a denser structure accompanied by a higher Young's modulus ${ }^{[43]}$ compared to pristine silica. 

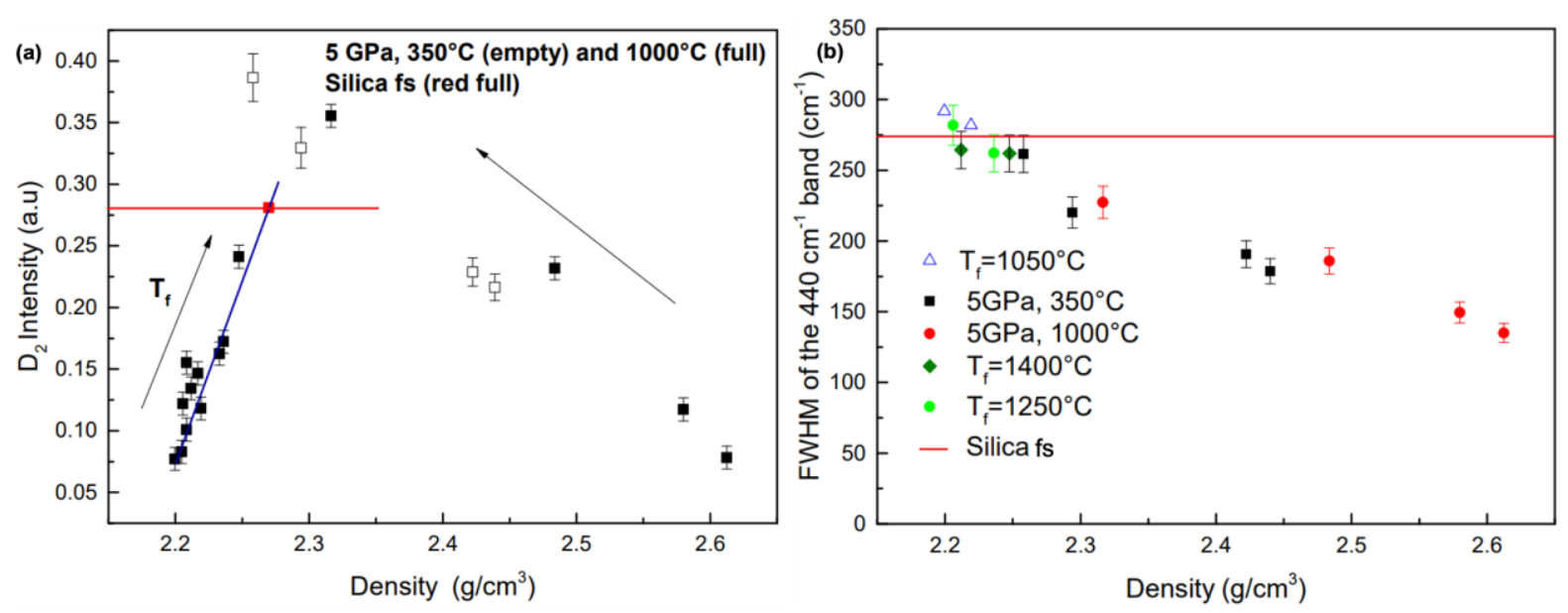

Figure 5. (a): Raman D2 band intensity as a function of density for HP-HT and $\mathrm{T}_{\mathrm{f}}$ samples. (b): FWHM of the $\mathrm{R}$-band as a function of density for HP-HT and $\mathrm{T}_{\mathrm{f}}$ samples. Both figures were extracted from ${ }^{[39]}$, and the results of the silica irradiated by femtosecond laser were inserted. Laser parameters: $\lambda=1030 \mathrm{~nm}, 100 \mathrm{kHz}, 100 \mu \mathrm{m} / \mathrm{s}$, $10^{3}$ pulses $/ \mu \mathrm{m}, \mathrm{NA}=0.16$, pulse duration $=250-300 \mathrm{fs}, \mathrm{E}=1.5 \mu \mathrm{J} /$ pulse.

In order to better quantify the observed variations to previously densified glasses $\left(T_{f}\right.$ and HP-HT) under irradiation (electrons vs femtosecond), the FWHM of the $440 \mathrm{~cm}^{-1}$ band and the D2 intensity from ${ }^{[39]}$ as a function of density are plotted in Figure 5. We can notice in Figure 5a that for density values lower than 2.3, the D2 band intensity increases linearly with the density, then decreases for higher density and we place here the D2 amplitude related to fs-Type II spectrum with the red line. Now, we compare this observation with the $440 \mathrm{~cm}^{-1}$ FWHM versus the glass density plotted in Figure 5b. It can be seen that the FWHM (i.e., the $\mathrm{Si}-\mathrm{O}-\mathrm{Si}$ angle dispersion) decreases when the silica glass density increases for all irradiated samples. This calibration curve leads to a rough estimate of the average density to be around 2.25-2.27 after fs-irradiation. This corresponds to a refractive index change of around $+10^{-2}$ ${ }^{[39]}$ in agreement with some anisotropic refractive index measurements early made by Bricchi et al. ${ }^{[12]}$. However, this is difficult to give a more reliable value at this step due to the composite nature of the probe volume that is made of an assembly of porous thin nanolayers (typ. $30 \mathrm{~nm}$ thickness) with densified interlayers (typ. 200-300 nm thickness) and some potential volume changes occurring around the nanopores as well. Given the nature of the densification process, a pure thermal mechanism, i.e. melting followed by fast quenching, can be exclude since it would not relax at temperatures below $T_{g}$ for such a short (30min) annealing time as we observed in Figure 4a. Interestingly, the estimated elastic properties of the densified interlayers are higher compared to a Type-I modification ${ }^{[43]}$. This suggests that the densification mechanism is more complex than the Regime-I modification. However, it is still unclear if the densification is due do defects accumulation (such as for electrons irradiation for instance) or from a more likely mechanism based on a high pressure-high temperature that develops during the nanogratings formation ${ }^{[44]}$.

\subsection{Observation of nanostructure thermal stability using Scanning Electron Microscope}

To further investigate the impact of annealing on the nanostructure changes, the samples were cleaved and observed by a Scanning Electron Microscope (SEM). Figure 5 displayed SEM micrographs for different annealing temperatures and laser polarization 


\section{WILEY-VCH}

direction. First, and from Figure 5c, some well-defined nanolayers could be observed at $1000{ }^{\circ} \mathrm{C}$. This observation is consistent with the results shown in Figure 2, where retardance (hence birefringence) can easily be detected. When the temperature is further increased to $1200{ }^{\circ} \mathrm{C}$, as shown in Figure $5 \mathrm{~d}$, we observed the disappearance of several layers. From Figure $5 \mathrm{a}, 5 \mathrm{~b}$, and $5 \mathrm{c}$, we make the observation that upon an increase of temperature the irradiated glass morphology evolves such that 1) the $2 \mathrm{D}$ porosity filling factor in the nanolayers (FF) decreases and 2) the averaged pore size slightly decreases and 3) the number of nanolayers decreases (the side nanolayers are less stable than the middle ones). These observations can be explained on the basis of the Rayleigh-Plesset (R-P) equation ${ }^{[35]}$, and where we observe that small pores are erased more quickly than larger ones. To help the reader, the main equations from the aforementioned reference are added in Appendix A. As a result, the ongoing erasure of the small pores population is no more included in the counting (due to the limited resolution of the SEM) to determine the average pore size diameter. This has an effect of "shifting up" the average pore size distribution to larger values. However, the filling factor still decreases as pores are progressively erased, which is in agreement with both the scattering measurements and the observation of a decrease in retardance upon temperature increase.
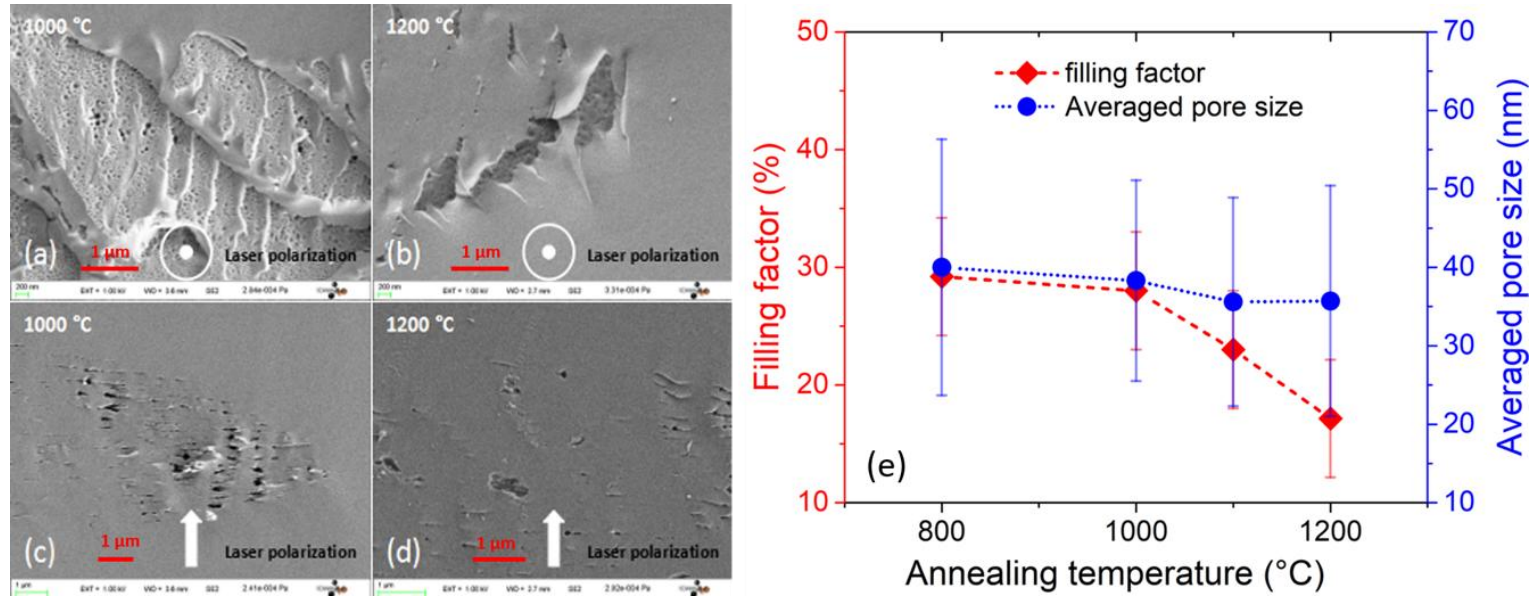

Figure 5. Scanning electron micrographs of Type II modification areas in silica glass annealed at $1000{ }^{\circ} \mathrm{C}$ and $1200{ }^{\circ} \mathrm{C}$, for parallel (a), (b) and orthogonal (c), (d) laser polarization direction with respect to the writing direction. (e) Evolution of the 2D porosity filling factor in the nanolayers (FF) and the average pore size diameter as a function of annealing temperature. The lines serve here only as guide-to-the-eye. Laser parameters: $\lambda=1030 \mathrm{~nm}, 100 \mathrm{kHz}, 100 \mu \mathrm{m} / \mathrm{s}, 10^{3}$ pulses $/ \mu \mathrm{m}, \mathrm{NA}=0.16$, pulse duration $=250-300 \mathrm{fs}, \mathrm{E}=1.2 \mu \mathrm{J} /$ pulse.

\section{Discussion}

\subsection{Summary and tentative decomposition of the measured retardance $\mathbf{R}_{\text {norm }}(T)$}

In this work we have highlighted the dependency of femtosecond laser modifications (including defects centers, densification, stress, distributed nanopores) with temperature. In the following section, we only consider birefringence contributions which only have proper axes along $\mathrm{x}$ or y i.e. $\delta \mathrm{LB}=\delta \mathrm{n}_{\mathrm{x}}-\delta \mathrm{n}_{\mathrm{y}}$ that can be $>0$ or $<0$. If this is not the case (e.g. X22 or X45 writing or the occurrence of shear-stress for instance), one needs to extract (e.g. using Mueller formalism) the contributions along both $\mathrm{x}$ and $\mathrm{y}$-axis before to do the summation. 


\section{WILEY-VCH}

Under this restrictive hypothesis, we can consider that the total measured birefringence is composed by additive/subtractive but not independent (e.g. stress is related to the permanent volume changes) contributions. In addition, they all present different erasure kinetics based on their thermal stabilities, as summarized in Figure 6.
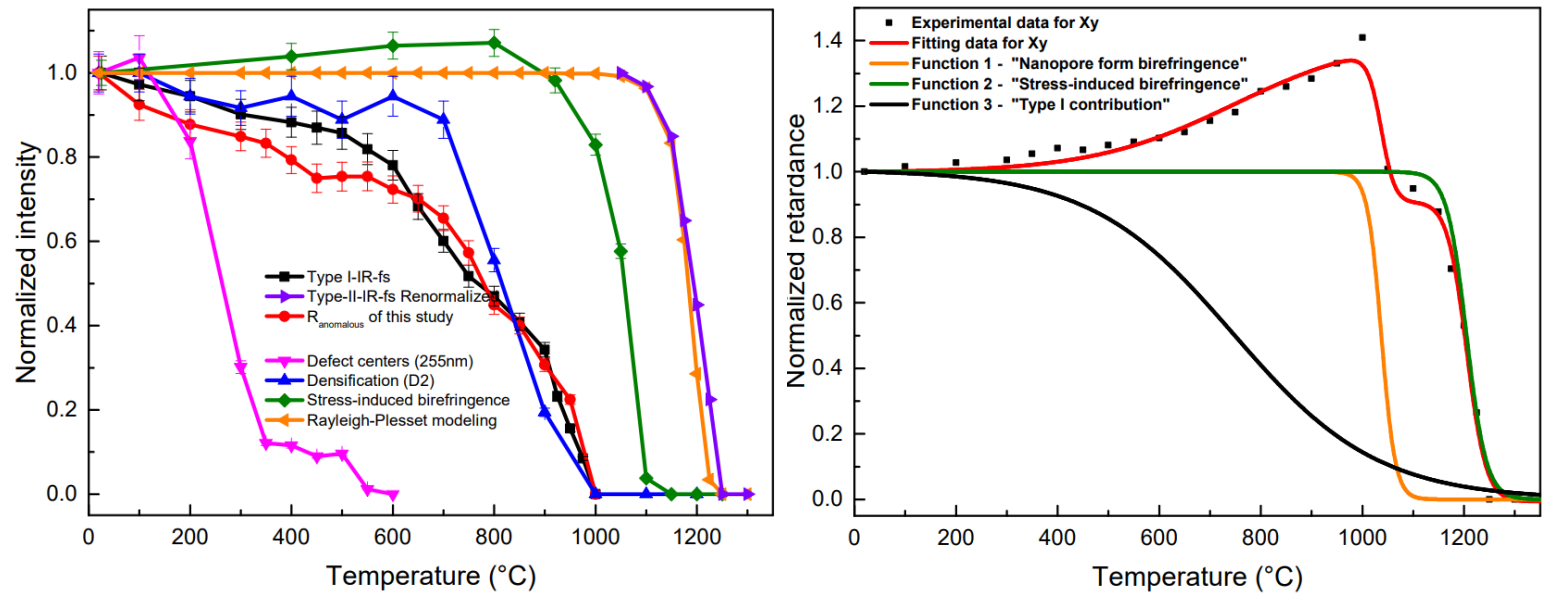

Figure 6. (a): Normalized index change $\Delta \mathrm{n}_{\text {TypeI }}(\mathrm{T})$ of Type I modification by IR fs-laser (black); $\mathrm{R}_{\text {anomalous }}(\mathrm{T})$ (red) is the renormalized "anomalous part" of the Type II (see text equation 1) (i.e. the $40 \%$ increment in Figure 2a). We also add D2 peak intensity (blue) and the SiODC defect (255nm) UV absorption intensity (pink); the stress-induced birefringence (green). In the highest $\mathrm{T}$ range, we have the simulation of the nanopores' erasure using the Rayleigh-Plesset (R-P) equation (orange, simulation conditions: the surface energy S $=0.3 \mathrm{~J} \cdot \mathrm{m}^{-2}$; pore size diameter $=70 \mathrm{~nm}$ ) and the normalized retardance (at $1050{ }^{\circ} \mathrm{C}$ ) of Type II (purple, $\mathrm{X} 45^{\circ}$ taken from Figure 2), as a function of the isochronal annealing temperature. (b): Decomposition of the normalized retardance $\mathrm{R}_{\mathrm{norm}}(\mathrm{T}, \delta \mathrm{t}=30 \mathrm{~min})$ for Xy sample using 3 components. The fitting curve (red) is composed of three sigmoidal functions that could be assimilated to "Nanopores " (orange), "Stress-induced birefringence" relaxing into a plastic deformation around nanopores (green) and "Type I like contribution" (black, the curve has been inverted for the purpose of the layout).

These contributions are divided into three categories:

- First the birefringence of the Type I-like modification can be considered as the combination of the defect, the densification and the proportional stress-induced birefringence to the previous two.

- Then Type II modification contains stresses from two different origins, the one of Type I modification that disappears with the erasure of type I modification at temperatures below plastic relaxation, and the second one coming from nanoporous layers will relax plastically (a plastic deformation around nanopores occurs) because nanopores are more stable and will ultimately erase at higher temperature.

- The third contribution is the form birefringence related to the nanopores arranged within nanolayers so-called nanogratings.

Following this view, we have performed a decomposition of the normalized retardance $\mathrm{R}_{\text {norm }}(\mathrm{T}, \delta \mathrm{t}=30 \mathrm{~min}$ ) for $\mathrm{Xy}$ sample (data are taken from Figure $2 \mathrm{a}$ ) using a 3 components model: Type I modification (black), stress that relax into a plastic deformation (green) and nanopores themselves (orange), as shown in Figure 6b. In the following we assume that the erasure kinetic of each component follows a sigmoidal evolution: 


$$
R_{n o r m}(t, T)=a\left(\frac{1}{1+(9) \frac{T-T_{0}}{\Delta t}}\right)
$$

In this equation " $a$ " represents the relative contribution to $\mathrm{R}_{\text {norm }}$ " $\mathrm{T}_{0}$ " is the temperature where the curve fall, and $\Delta_{T}^{\delta t}$ (in $\mathrm{K}$ ) regulates the slope of decay. Due to the numerous fitting parameters, we have chosen to initiate the coefficients " $\mathrm{T}_{0}$ " based on the results shown in Figure 6a. The fitted values of a, $\mathrm{T}_{0}$, and $\Delta_{T}^{\delta t}$ are reported in Table 1 . Note that in the VAREPA framework developed by Poumellec et al. ${ }^{[45]}$ we can tentatively give a physical meaning to these parameters. Some details of the framework are described in Appendix B. $\mathrm{T}_{\mathrm{o}}$ is related to the center of activation energy distribution $E_{0}=k_{B} T_{0} \ln \left(k_{o} \delta t\right)$ and $\Delta_{T}^{\delta t}$ to the FWHM $\Delta_{\mathrm{E}}$ of the distribution that can be rewritten as $\Delta_{E}=k_{B} \Delta_{T}^{\delta t} \ln \left(k_{o} \delta t\right)$.

\begin{tabular}{cccc}
\hline Coefficient & $\begin{array}{c}\text { Nanopore form } \\
\text { birefringence } \delta \mathbf{L B}_{\text {form }}\end{array}$ & $\begin{array}{c}\text { Stress-induced } \\
\text { birefringence } \delta \mathbf{L B}_{\text {stress }}\end{array}$ & "Type I-like" contribution \\
\hline $\mathbf{a}$ & $0.941 \pm 0.022$ & $0.476 \pm 0.026$ & $-0.417 \pm 0.024$ \\
\hline $\mathbf{T}_{\mathbf{0}}$ (in K) & $1478.3 \pm 2.1$ & $1310.4 \pm 4.7$ & $1020.3 \pm 37.0$ \\
\hline${ }_{\boldsymbol{T}}^{\boldsymbol{t}}$ (in K) & $42.29 \pm 4.0$ & $30.01 \pm 2.50$ & $310.81 \pm 29.16$ \\
\hline
\end{tabular}

Table 1. Coefficients values of the fitting using Eq. (1) for each of the 3 contributions.

Now by comparing the three components to Figure $6 \mathrm{a}$ and in particular $\mathrm{T}_{0}$ values to the inflexion point of the curves in Fig. 6a, we can tentatively assimilate each function to a mechanism and its relative "weight" to the overall measured retardance. The first function represents the major contribution $(\mathrm{a}=0.94)$ of the nanopores, which should be erased around $1250^{\circ} \mathrm{C}$. Then the second function can account for the stress-induced birefringence contribution $(\mathrm{a}=0.48)$, which can last until $1100^{\circ} \mathrm{C}$. Finally, we can subtract the third function that we attributed to Type I-like modification $(\mathrm{a}=-0.42)$ to fit the anomalous increase of the retardance in the room $\mathrm{T}-1000^{\circ} \mathrm{C}$ range.

In Table 2 we classified and summarized the different category of mechanisms (labeled A, B, and $\mathrm{C}$ in Table 2) that could induce birefringence within the nanogratings formation regime along with their contribution to the total birefringence and thermal stability. We focus our analysis upon two major modification aspects, which are refractive index changes $(\delta n)$ and linear birefringence $(\delta \mathrm{LB})$ that may be due to either form birefringence or stress-induced birefringence. These contributions (from Figure 6 and Table 2) are discussed in the next sections. 
WILEY-VCH

Table 2. Summary of the different potential contribution of total birefringence within nanogratings regime.

\begin{tabular}{|c|c|c|c|c|}
\hline $\begin{array}{l}\text { Primary } \\
\text { mechanism }\end{array}$ & Subcases & Index contribution $\delta n_{i}$ & $\begin{array}{l}\text { Birefringence contribution }{ }^{a)}: \delta L B=\delta n_{x}-\delta n_{y} \\
\text { Note that } \delta L B \text { can be }>0 \text { or }<0 \text {. }\end{array}$ & $\begin{array}{l}\text { Contribution } \\
\text { quantity/thermal } \\
\text { stability }\end{array}$ \\
\hline \multirow{4}{*}{$\begin{array}{c}\text { A } \\
\text { fs-Type-II } \\
\text { Birefringence } \\
\begin{array}{c}\text { (due to nanopores } \\
\text { formation) }\end{array}\end{array}$} & $\begin{array}{l}\text { Case A1: Spherical nanopores distributed } \\
\text { uniformly in the nanolayers of refractive } \\
\text { index } n_{1}\end{array}$ & $\begin{array}{l}(1-F F)\left(\frac{\varepsilon_{e f f}-\varepsilon_{m}}{\varepsilon_{m}+2 \varepsilon_{e f f}}\right)=F F\left(\frac{\varepsilon_{i}-\varepsilon_{e f f}}{\varepsilon_{i}+2 \varepsilon_{e f f}}\right) \\
n_{1}=\sqrt{\varepsilon_{e f f}}=\sqrt{n_{m}^{2} \frac{n_{m}^{2}+\frac{(1+2 F F)}{3}\left(n_{i}^{2}-n_{m}^{2}\right)}{n_{m}^{2}+\frac{(1-F F)}{3}\left(n_{i}^{2}-n_{m}^{2}\right)}}, \mathrm{n}_{2}{ }^{\mathrm{d})}\end{array}$ & $\begin{array}{l}\text { Form birefringence } \delta \mathrm{LB}_{\text {form }} \text { (negative uniaxial) } \\
\text { Slow axis is along nanolayers i.e; perpendicular to the } \\
\text { laser polarization orientation } \mathrm{E}\end{array}$ & \multirow{3}{*}{$\begin{array}{l}\text { Contribution: } \\
\text { Main contribution to } \\
\text { the measured LB or } \\
\text { Retardance } \\
\text { Range of thermal } \\
\text { erasure: }\end{array}$} \\
\hline & $\begin{array}{l}\text { Case A2a: Oblate or cylindrical nanopores } \\
\text { randomly oriented in the probe volume }\end{array}$ & Same as above & None due to the random orientation & \\
\hline & $\begin{array}{l}\text { Case A2b: Oriented oblate or cylindrical } \\
\text { nanopores (without layers) - like Type X low } \\
\text { loss modification }{ }^{[46]}\end{array}$ & $\begin{array}{c}\varepsilon_{e f f \|}=\varepsilon_{m}+F F\left(\varepsilon_{i}-\varepsilon_{m}\right)^{\mathrm{b})} \\
\varepsilon_{e f f \perp}=\varepsilon_{m}+\frac{F F\left(\varepsilon_{i}-\varepsilon_{m}\right)}{1+(1-F F)\left(\varepsilon_{i}-\varepsilon_{m}\right) / 2 \varepsilon_{m}}\end{array}$ & $\begin{array}{l}\text { Form birefringence } \delta L_{\text {torm }} \\
\text { Slow axis is parallel to the long axis of nanopores }{ }^{[46]}\end{array}$ & \\
\hline & $\begin{array}{l}\text { Case A3: Permanent volume expansion et } \\
\text { compressive elastic strain }{ }^{[47]} \text { e) }\end{array}$ & $\begin{array}{l}\text { Refractive index } n_{1} \text { decreases } \\
\text { (Lorentz-Lorenz + Pockels) }\end{array}$ & $\begin{array}{l}\text { Stress birefringence } \delta \mathrm{LB}_{\text {stress; }} \\
\text { Slow axis parallel to the scanning direction (for lines) } \\
\delta \mathrm{LB}_{\text {stress }}(>0 \text { for } \mathrm{X} \text { writing) }\end{array}$ & $\begin{array}{l}\text { Contribution: } \\
\text { e.g. } \varepsilon^{p}=0.005 \text { leads to } \\
\delta L B_{\text {stress }}=0.0012 \\
\text { Range of thermal } \\
\text { erasure: }\left(800^{\circ} \mathrm{C}-\mathrm{T}_{\mathrm{a}}\right)\end{array}$ \\
\hline \multirow{3}{*}{$\begin{array}{c}\text { B } \\
\text { Point defects }\end{array}$} & $\begin{array}{l}\text { Case B1: Anisotropic and oriented defects } \\
\text { uniformly distributed in the laser track }\end{array}$ & $\begin{array}{l}\Delta \mathrm{n}_{\mathrm{ii}} \text { increase, higher } \Delta \mathrm{n}_{\mathrm{ii}} \text { along the high } \\
\text { absorption axis }\end{array}$ & $\begin{array}{l}\left.\delta \mathrm{LB}_{\text {defects }}>0 \text { ( } \alpha_{\text {high }} \text { along } \mathrm{x}\right),<0\left(\alpha_{\text {high }} \text { along } \mathrm{y}\right) \\
\text { Slow axis is along high absorption } \alpha_{\text {high }} \text { direction }\end{array}$ & \multirow{2}{*}{$\begin{array}{l}\text { Contribution: } \\
\text { LB or Retardance } \\
\text { contribution usually } \\
\text { limited to less than } \\
5 \%{ }^{[37]}\end{array}$} \\
\hline & $\begin{array}{l}\text { Case B2a: Isotropic defect (or anisotropic } \\
\text { defects randomly oriented) distributed } \\
\text { between the nanolayers }\left(\mathrm{n}_{2}\right)\end{array}$ & $\mathrm{n}_{2}$ increases (Kramers-Kronig) & $\mathrm{LB}_{\text {form }}$ increases & \\
\hline & $\begin{array}{l}\text { Case B2b: Isotropic defect (or anisotropic } \\
\text { defects randomly oriented) distributed inside } \\
\text { the porous nanolayers }\left(n_{1}\right)\end{array}$ & $\mathrm{n}_{1}$ increases (Kramers-Kronig) & $\mathrm{LB}_{\text {form }}$ decreases & $\begin{array}{l}\text { Range of thermal } \\
\text { erasure: } \\
\left(200^{\circ} \mathrm{C}-500^{\circ} \mathrm{C}\right)\end{array}$ \\
\hline \multirow{4}{*}{$\begin{array}{c}\text { C } \\
\text { Densification }\end{array}$} & $\begin{array}{l}\text { Permanent densification and associated } \\
\text { tensile strain }\end{array}$ & $\begin{array}{l}\text { Refractive index } \Delta \mathrm{n} \text { increase } \\
\text { (Lorentz-Lorenz + Pockels) }\end{array}$ & & \multirow{4}{*}{ 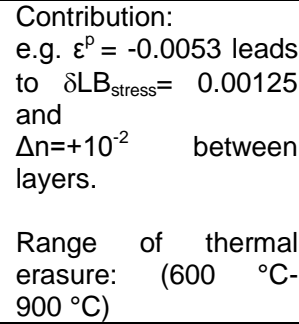 } \\
\hline & $\begin{array}{l}\text { Case C1: Uniform along the laser track as a } \\
\text { "separate layer" }\end{array}$ & $\mathrm{n}_{1}$ and $\mathrm{n}_{2}$ increases & $\begin{array}{l}\text { Stress birefringence } \delta \mathrm{LB}_{\text {stress }} ; \\
\text { Slow axis perpendicular to the scanning direction (for } \\
\text { lines geometry) } \\
\delta L B_{\text {stress }}(<0 \text { for } \mathrm{X} \text { writing and }>0 \text { for } \mathrm{Y} \text { writing) }\end{array}$ & \\
\hline & Case C2a: Within the porous nanolayers & $n_{1}$ increases & $\mathrm{LB}_{\text {form }}$ decreases & \\
\hline & Case C2b: Between the nanolayers & $\mathrm{n}_{2}$ increases & LB $_{\text {form }}$ increases & \\
\hline
\end{tabular}

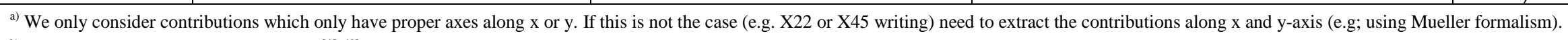

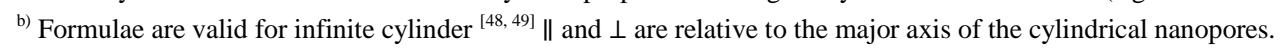

${ }^{c} \varepsilon_{\text {eff }}$ the dielectric constant for the composite (e.g. nanoporous layers), $\varepsilon_{\mathrm{i}}$ for the inclusion (here nanopores), $\varepsilon_{\mathrm{m}}$ for the surrounding medium (e.g. silica, understoichiometric silica, densified silica);

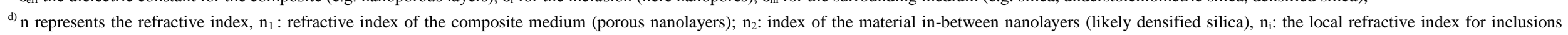
(nanopores). $\mathrm{FF}=$ porosity $3 \mathrm{D}$ filling factor; $\mathrm{n}_{\mathrm{m}}$ : index for the surrounding medium (between the nanopores in the nanoplanes:);

${ }^{\mathrm{e})} \varepsilon^{\mathrm{p}}$ represents the permanent strain due to specific volume changes; $\varepsilon^{\mathrm{e}}$ is for elastic strain due to the material response; whereas $\sigma$ represents the stress;

${ }^{\mathrm{f})} \mathrm{T}_{\mathrm{a}}=$ Glass annealing point (temperature where the glass viscosity is set at $\eta=10^{12}$ Pa.s). 


\section{WILEY-VCH}

\subsection{Overview of the different contribution to the measured birefringence}

\section{Case A: Contribution of nanopores formation within Type II regime}

At this point, it is worth pointing out that the main contribution to the aggregate birefringence is usually attributed to the nanogratings form birefringence $\mathrm{LB}_{\text {form }}$ in close relationship with the formation of nanopores in aligned nanoplans and related volume expansion as summarized in the cases $A 1$ and $A 3$ of Table 1. For more details on these contributions, we recommend the reader the following articles: ${ }^{[35,44,50]}$. Note that recently Sakakura et al. ${ }^{[46]}$ have reported some low loss birefringent modifications qualified of Type $\mathrm{X}$ modifications. As described shortly in case A2 of Table 1, the form birefringence was attributed to the formation of oblate and oriented nanopores (case $A 2 b$ ) with a slow axis parallel to the long axis of the nanopores.

Case A1: From the SEM micrographs displayed in Figure 5, we can deduce the changes in morphology (e.g., porosity, filling factor) with respect to the annealing thermal treatment. Very recently, Cavillon et al. ${ }^{[35]}$ have shown the correlation between the thermal stability of anisotropic optical properties and the erasure of the nanopores present in the nanogratings. Briefly, in the perpendicular configuration $\mathrm{Xy}$, although several nanolayers gradually dissolved, we noticed that the average spacing between the remaining nanolayers does not change with the annealing temperature.

On the other hand, in the parallel configuration $\mathrm{Xx}$, the number of nanopores and the average pore size for each laser track is found to decrease as the temperature increases. Additionally, these results indicate that all nanopores tend to become smaller by the same quantity (in agreement with the scattering signature in Fig. 3) thus the smallest pores (e.g., 20 to $30 \mathrm{~nm}$ long) disappear (typ. diameter around 70-90 nm) for thermal treatments above $1000{ }^{\circ} \mathrm{C}$ and up to $1200{ }^{\circ} \mathrm{C}$ in silica. As a result, the average pores size does not decrease so much than with a proportional size decrease and the porosity filling factor FF decreases as the annealing temperature increases.

By using the Rayleigh-Plesset (R-P) equation to simulate the erasure of the pores (see details in Annex1), the evolution of the normalized retardance $\mathrm{R}$ could be calculated for a given pore size diameter and glass material. In Figure 6 (SuprasilCG modeled curve, the orange solid line), the nanopore erasure is displayed by using the R-P equation, and the evolution of the normalized retardance was also calculated. The experimental curve (SuprasilCG curve $\mathrm{X} 45^{\circ}$, the purple solid line) is used to compare, the measured data follows the same experimental condition and removing the anomalous increase. Then, it is normalized relative to the sharp retardance decrease at the highest annealing temperature values that we hypothesized here to be characteristic of the nanopore erasure. These two curves show quite similar trends in Figure 6. More details can be found in ${ }^{[35]}$, and leads to the conclusion that the porosity could play an extremely important role in the erasure of nanogratings and their associated birefringence in a high temperature regime. In particular, the R-P equation sheds light on the major role played by the temperature dependence of the glass viscosity on the thermal stability of fs-induced Type II modifications. The viscous behavior of the glass, at high temperature, is the major parameter that drives the nanogratings erasure and related form birefringence. Current research efforts are ongoing to better understand the role played by the 


\section{WILEY-VCH}

nanopores, within the nanoporous regions, on the overall thermal stability of the laser induced Type II modifications.

\section{Case A3: Contribution of the stress-induced birefringence within type II regime}

Usually when performing step isochronal annealing, within the last decade a few research groups have shown the presence of a zone of mechanical stresses ${ }^{[51-53]}$, possibly associated with birefringence properties in the irradiated zone, related to the polarization of the writing laser beam ${ }^{[47]}$. Within Type II regime, the nanolayers are made of porous material and our group has suggested they are created by glass decomposition during the laser interaction within the hot plasma nanolayers ${ }^{[7]}$. During the decomposition of $\mathrm{SiO}_{2}$, many nanopores or nanocavities are created within these layers leading to a net glass volume expansion ${ }^{[44,54]}$, which correlates with the formation of porous nanogratings ${ }^{[7,55]}$. This corresponds to the appearance of a permanent strain $\varepsilon^{p}>0$ within Type II zones (whereas it is negative for a glass densification within Type I regime) and thus $\Delta \mathrm{n}<0$ in the laser-affected volume. The later results into a negative elastic strain $\varepsilon^{\mathrm{e}}<0$ as a direct elastic response of the material, and therefore a compressive elastic strain field within and around the laser-modified region. Finally based on the photo-elasticity theory, stress-induced birefringence $\mathrm{LB}_{\text {stress }}$ has been observed that finally participates to the total measured birefringence LB as summarized in case A3 of Table 1. Depending on the laser exposure conditions, the overall stress can be enhanced or minimized ${ }^{[44]}$ leading to tunable birefringence values from $10^{-5}$ up to $\sim 10^{-3}[56-58]$.

Note that the slow axis direction is mostly determined by the geometry of the irradiated regions and does not depend on the laser writing polarization as a first approximation (except at the edges of the written line) ${ }^{[47]}$. For single lines or superposition of lines, there is a quasi-uniaxial loading and the slow axis direction of the stress-induced birefringence is parallel to the lines for volume expansion ${ }^{[33]}$ and perpendicular to the lines for a densification. As a first approximation, considering a "pure type II" modification (without any associated type I nor densified volume): if we combine the $\mathrm{LB}_{\text {form }}$ and the $\mathrm{LB}_{\text {stress }}$, we will have either additive or subtractive superposition of these two components. For Xx writing configuration (the slow axis from two components are perpendicular) we will have a subtractive superposition, whereas it is an additive superposition for Xy (the slow axes of the two components are parallel) writing configuration. For intermediate configurations (e.g. $\mathrm{X} 22^{\circ}$ ), there is a need to extract (e.g. using Mueller formalism) the LB components before to calculate the results of the superposition. Then under thermal treatment a part of the stress is expected to relax when approaching a temperature around $0.8 \times \mathrm{T}_{\mathrm{g}}$ for a few hours or $0.9 \times \mathrm{T}_{\mathrm{g}}$ for a few tens of minutes ( $\mathrm{T}_{\mathrm{g}}$ is the glass transition temperature). In our experiments, this starts from $800{ }^{\circ} \mathrm{C}$ as shown in Figure 6 (stress curve; the green solid line), which correlates with the " 1 st component" decay of $\mathrm{R}_{\text {norm }}(\mathrm{T})$ in the $1000-1000{ }^{\circ} \mathrm{C}$ range seen in Figure $2 \mathrm{a}$. We note here that the compressive stress field produced by the nanoporous layers does not disappear with the annihilation of the nanopores themselves (which takes place at a higher temperature) but by plastic deformation of the glass around the nanopores. This is not the case with the tensile stress field associated with the densification for which it disappears because the "producer" disappears.

\section{Case B: Contribution of point defects remains quite limited}




\section{WILEY-VCH}

In addition to the well-known existence of both form birefringence and stress-induced birefringence, Type II modifications in silica glass also contain a variety of point defects. Through their optical absorption bands, they are contributing to the observed refractive index changes $\Delta \mathrm{n}$ as usually described by the Kramer-Kronig (KK) relationship. Generally, most defects are absorbing in the UV-VUV range and they are contributing positively to $\Delta \mathrm{n}$ measured in the Vis-Near-IR range. This contribution decreases when the defects are bleached under thermal treatment. Therefore, their existence may also affect $\left(\mathrm{n}_{1}, \mathrm{n}_{2}\right)$ and thus the form birefringence $\mathrm{LB}_{\text {form }}$ (and thus the measured retardance $\mathrm{R}$ ) that is mostly attributed to the nanogratings form birefringence in the literature ${ }^{[12]}$. Different cases are described in Table 1 but we can think about two main cases: 1) anisotropic and oriented defects and 2) isotropic defects but uniformly distributed only inside nanolayers (not in-between). Both of 1) and 2) can create some small amount of birefringence.

- Case B1: The first possibility would be the formation of anisotropic and oriented defects that creates linear dichroism and thus linear birefringence through KK relationship. Linear dichroism was observed recently but only at wavelengths of around 1.2-1.4 $\mu \mathrm{m}^{[33]}$. In addition, there is apparent linear dichroism in the UV-Vis range, which has been attributed to polarization dependent light scattering ${ }^{[33]}$. Indeed, the arrangement of porous nanolayers creates anisotropic light scattering resulting in a linear diattenuation (rather than linear dichroism) tail observed in the UV-Vis range ${ }^{[33]}$ but no dichroic bands have been observed in this range ${ }^{[33]}$.

- Case B2: The second possibility is about the spatially distribution of isotropic defects absorbing in UV, there are two subcases. Case B2a): on one hand, the defects are preferentially located between the nanolayers (region of index $n_{2}$ in Figure 1). When they are bleached under thermal treatment, $\mathrm{n}_{2}$ decreases and therefore $\mathrm{LB}_{\text {form }}$ (proportional to $\mathrm{n}_{2}-\mathrm{n}_{1}$, and with $\mathrm{n}_{1}<\mathrm{n}_{2}$, initially) decreases. Case B2b): On the other hand, the defects are formed inside the nanolayers (area of index $\mathrm{n}_{1}$ in Figure 1) especially in the material surrounding $\mathrm{n}_{\mathrm{sg}}$ the nanopores. When they disappear during the heat treatment, the refractive index $\mathrm{n}_{\mathrm{sg}}$ (and $\mathrm{n}_{1}$ ) decreases and thus $\mathrm{LB}_{\text {form }}$ increases resulting in an increase of $R$.

Correlating the Figure 2 and Figure 3, most defects have been bleached around $400{ }^{\circ} \mathrm{C}$ whereas there is no significant effect or maybe a slight increase of the measured retardance within this range of temperatures (see Figure 2a). In summary, compared with the form birefringence and the stress-induced birefringence, the defects play a minor role in the total retardance response induced within nanogratings regime. This is in agreement with previous work where silica samples were annealed for 2 hours at $450{ }^{\circ} \mathrm{C}$. All point defects generated within Type I modifications were completely erased ${ }^{[37]}$ whereas the overall retardance value was observed to decrease only by less than $5 \%{ }^{[37]}$.

\section{Case C: Contribution of permanent densification within Type II regime}

Now considering that densification annealed out at lower temperature than nanopores themselves, this could impact the measured birefringence through two different mechanisms: 1) by affecting the nanogratings refractive index changes $n_{1}$ and $n_{2}$ and thus $L B_{\text {form }}$ and/or 2 ) through the direct contribution of stress-induced birefringence $\left(\delta \mathrm{LB}_{\text {stress }}\right)$ to the measured total LB. Additionally, as summarized in Table 1, one has to consider different possibilities since 


\section{WILEY-VCH}

densification can happen: Case Cl-along the laser track (e.g. in the tail) bringing an additional stress-birefringence contribution and/or Case C2- within Type II regions as suggested by Bellouard ${ }^{[59]}$ and Poumellec ${ }^{[60]}$. About the second case and considering the « periodical structure » of the nanogratings, densification might be mostly present either between the nanolayers $\left(n_{2}\right)$ or in the material surrounding the nanopores $n_{s g}$ within the nanolayers themselves $\left(\mathrm{n}_{1}\right)$.

- Case C2a: We can first assume that densification is present in the material surrounding the nanopores (of refractive index $\mathrm{n}_{\mathrm{sg}}$ in Figure 1). From our data and the literature ${ }^{[23]}$ we expect that densification will be erased at a much lower temperature than the nanopores themselves. Hence, as the annealing temperature increases, densified regions will gradually anneal away, causing a decrease of the refractive index $\mathrm{n}_{\mathrm{sg}}$ and thus $\mathrm{n}_{1}$ within the porous nanolayers (see Figure 1). Consequently, $\mathrm{LB}_{\text {form }}$ increases and therefore we have an increase in the measured LB (or retardance $\mathrm{R})$.

- Case $C 2 b$ : Now, if we assume that that densification is preferentially located inbetween the nanolayers, this should result in a decrease of the $\mathrm{LB}_{\text {form }}$ under thermal treatment. This agrees with early results of Bricchi et al. ${ }^{[12]}$ showing a $n_{2}$ increase up to a few $10^{-2}$ whereas P. Vlugter et al. ${ }^{[43]}$ has recently revealed an increase of the Young modulus in the silica material between porous nanolayers associated to an increase of material density also suggested by Raman spectroscopy. Assuming a densification contribution $\Delta \mathrm{n}_{2}=10^{-2}{ }^{[12]}$ and some typical values of $\mathrm{n}_{1}(1.3), \mathrm{n}_{2}$ (1.46), one can calculate the $\mathrm{LB}_{\text {form }}$ changes. When this contribution vanishes under thermal treatment, one found a decrease of around $20-30 \mathrm{~nm}$ for a total retardance of $270 \mathrm{~nm}$ so $<10 \%$.

- Now taking into account the stress contribution in the above-mentioned cases, the LB (or Retardance) measurements correspond to two "additive" contributions LB $_{\text {stress }}+$ $\mathrm{LB}_{\text {form. }}$. But one needs to consider several difficulties, including spatial distribution in depth (overlapping or not like case C1) and the respective neutral axis orientation of these contributions, which can lead to additive or subtractive effects depending on the respective slow axis orientation.

\section{On the origin of the unexpected increase of the retardance within room $\mathrm{T}-1000^{\circ} \mathrm{C}$}

Usually when performing step isochronal annealing, we observe a monotonous decay of the laser-induced refractive index changes ${ }^{[16]}$ as it is also the case here for the low energy Type II $(0,85 \mu \mathrm{J} /$ pulse $)$ or for Type I modifications. However as shown in Figure $2 \mathrm{a}$ for the three 'high energy' samples, we observed an unexpected behavior namely a slight increase (a few $\%$ ) of $\mathrm{R}_{\text {norm }}(\mathrm{T})$ in the $100-500^{\circ} \mathrm{C}$ followed by a strong one (up to $40 \%$ !) from $550{ }^{\circ} \mathrm{C}$ $1000{ }^{\circ} \mathrm{C}$. Such behavior was already observed both in bulk silica and in Ge-doped optical fibers ${ }^{[12,23]}$ but less pronounced. It was suggested that the co-existence of Type I modifications (defects and densification) within nanogratings could explain this behavior ${ }^{[12,}$ ${ }^{23}$. More precisely it has been suggesting that the slight increase observed below $500^{\circ} \mathrm{C}$ is attributed to point defects bleaching whereas at higher temperature is rather related to the relaxation of the permanent densification. Now by comparing and analyzing the characteristic curves shown in Figure 6, we could tentatively explore the relationship between this 


\section{WILEY-VCH}

unexpected increase ${ }^{[23]}$ and the different erasure mechanisms. In this view, we have first renormalized the $\mathrm{R}_{\text {norm }}(\mathrm{T})$ "anomalous increase" of Type II curve (the red solid line in Figure 6) as follows:

$$
R_{\text {anomalous }}(T)=\frac{R\left(1000^{\circ} \mathrm{C}\right)-R(T)}{R\left(1000^{\circ} \mathrm{C}\right)-1} \text { for } \mathrm{T}<1000^{\circ} \mathrm{C} . \text { Eq. } 2
$$

Then for sake of comparison, we inserted in Figure 6 the normalized refractive index changes of Type I modifications (black solid line), labeled $\Delta \mathrm{n}_{\text {Type I-IR-fs }}(\mathrm{T})$, as a function of annealing temperature. Both curves $\mathrm{R}_{\text {anomalous }}(\mathrm{T})$ and $\Delta \mathrm{n}_{\text {Type I-IR-fs }}(\mathrm{T})$ follow similar trends, i.e., a slow decay from room temperature up to $500{ }^{\circ} \mathrm{C}$, a steeper decrease starting around $600{ }^{\circ} \mathrm{C}$ and a full erasure at $1000{ }^{\circ} \mathrm{C}$. The initial decay of $\Delta \mathrm{n}_{\text {Type I-IR-fs }}(\mathrm{T})$ is usually related to point defects erasure (up to $400^{\circ} \mathrm{C}$ ) whereas the main part might be attributed to the relaxation of glass densification. In silica this is usually supported by micro-Raman spectroscopy since the D2 band intensity shows a significant decay starting from $600{ }^{\circ} \mathrm{C}$ up to $1000{ }^{\circ} \mathrm{C}$ (see the blue curve in Figure 6).

For going further in the tentative explanation let's focuses on the case $C 2 b, \mathrm{LB}_{\text {stress }}$ contains two components: a positive contribution (tensile stress) in response to the permanent

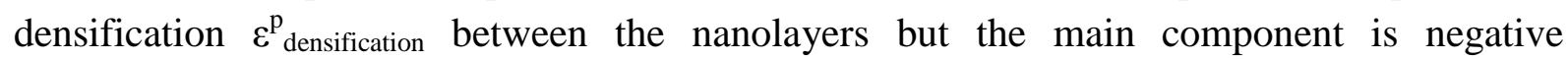
(compressive stress) due to nanolayers volume expansion $\varepsilon^{\mathrm{p}}$ expansion ${ }^{[44]}$. Therefore, the thermal relaxation of the densification $\left(\varepsilon^{\mathrm{p}}\right.$ densification vanishes within the $600-900{ }^{\circ} \mathrm{C}$ range $)$ will result in a higher net volume expansion. Thus the compressive stress and $\mathrm{LB}_{\text {stress }}$ will become higher in agreement with the green curve in Figure 6. We note that the tensile stress associated to densification relaxes but the compressive one related to the volume expansion still remain until higher temperatures. Quantitatively, $\mathrm{LB}_{\text {stress }}$ amplitude usually remains quite low ${ }^{[59]}$ but it cumulates from pulse to pulse and lines to lines considering our writing geometry that favors stress acummulation ${ }^{[33]}$. A rough estimate of $\mathrm{LB}_{\text {stress }}$ changes when relaxing permanent strain $\varepsilon_{\text {densification }}^{\mathrm{p}}(<0)$ can be done. Assuming an initial $\Delta \mathrm{n}_{2}=10^{-2}$, then calculating $\varepsilon^{\mathrm{p}}$ using the Lorentz-Lorenz equation and an estimate of elastic strain $\varepsilon^{\mathrm{e}}$ based on our writing geometry. Finally, we found from photo-elastic equations an $\mathrm{LB}_{\text {stress }}$ that could reach 60-100 nm (for a total of $270 \mathrm{~nm}$ ), which agrees rather well with the unexpected increase (up to 40\%) of the measured retardance $R_{\text {norm }}(T)$ in Figure $2 a$.

\subsection{Influence of the laser parameters on fs-Type II (nanogratings) thermal stability}

Laser parameters can impact the thermal stability of laser-induced refractive index changes ${ }^{[16]}$, including within the Type II regime. In the particular framework of this paper, both the relative contribution of each mechanism and the final steep decay (attributed to the erasure of the nanopores ${ }^{[35]}$ ) will be altered by the different laser writing parameters.

For instance, laser-writing speed has been proved to be one of the key factors. Our previous work has revealed that higher speed (e.g. $10 \mathrm{~mm} / \mathrm{s}$ instead of 1 or $0,1 \mathrm{~mm} / \mathrm{s}, 2$ $\mu \mathrm{J} /$ pulse, $1030 \mathrm{~nm}, 250 \mathrm{fs}, 100 \mathrm{kHz}, \mathrm{NA}=0.6$ ) leads to higher thermal stability in $\mathrm{SiO}_{2}$ that can be attributed to larger nanopores generated during fs-irradiation as confirmed by SEM ${ }^{[31]}$. High pulse energy also makes higher thermal stability modifications with the erasure constant $\mathrm{k}_{0}$ of the nanogratings that was increasing from $2.10^{5}\left(1 \mu \mathrm{J} /\right.$ pulse) to $7.10^{5} \mathrm{~s}^{-1}$ for $1.75 \mu \mathrm{J} / \mathrm{pulse}$ (800 nm $700 \mathrm{fs}, 0.16 \mathrm{NA}, 200 \mathrm{kHz}, 1 \mathrm{~mm} / \mathrm{s}$, Xy configuration) ${ }^{[18]}$. As shown in Figure. 2, we found as well that the square written a low energy $(0.8 \mu \mathrm{J} /$ pulse $)$ exhibits a lower thermal 


\section{WILEY-VCH}

stability than for $1.75 \mu \mathrm{J} /$ pulse, especially in the intermediate temperature range $\left(500^{\circ} \mathrm{C}\right.$ $1000^{\circ} \mathrm{C}$ ). The key difference here seems relegated to the relative contribution of Type I-like modifications (like interlayers densification) within Type II regime. Such thermal stability that depends on the writing pulse energy was also observed in Ge-doped $\mathrm{SiO}_{2}$ optical fibers (SMF28 and a 3D printed fibers) ${ }^{[61]}$ where the final steep decay is shifted towards high $\mathrm{T}$ at high pulse energy. Again we likely could attribute this effect to larger size of the nanopores generated by the higher pulse energy in agreement with SEM observations ${ }^{[35]}$.

Something maybe less expected, the writing configuration has a significant impact on the thermal stability. Indeed lines ${ }^{[62]}$ or squares ${ }^{[18]}$ written using Xx configuration exhibits higher thermal stability $\left(\mathrm{k}_{0}=\mathrm{a}\right.$ few $\left.10^{7} \mathrm{~s}^{-1}\right)$ than Xy $\left(\mathrm{k}_{0}=\mathrm{a}\right.$ few $\left.10^{5} \mathrm{~s}^{-1}\right)$ but the reasons are still unclear. In this work, some significant differences could be observed between the 3 investigated configurations in the intermediate temperature range $\left(500^{\circ} \mathrm{C}-1000^{\circ} \mathrm{C}\right)$. In particular the stress-induced birefringence contribution is quite different according to the polarization orientation (higher for Xy writing, in agreement with ${ }^{[47]}$ whereas the final steep decay remains quite similar.

On the other hand, the relative contributions of each mechanism will indeed vary according to pulse energy, scanning speed, numerical aperture, pulse duration but with the writing geometry as well (dots, single lines, array of lines. etc...). Firstly, based on the results demonstrated in most publications (bulk or fibers), it can be deduced that the defects centers exhibit a minor contribution (typ. below 5\%) to the measured LB, which is in line with what we discussed above. Note that defects can be bleached without affecting the other contributions. The typical densification contribution can be roughly estimated from results of [44] that measures the volume changes according to the total deposited dose in various experimental conditions. In contrast, it is more complicated for the situation of stress-induced birefringence since it cumulated from pulses to pulses and with the energy. In addition to this, it also depends on the geometry (single lines or lines array, line to line distance) ${ }^{[33,44]}$, it can vary from 5-10\% of the TLB for a single line writing and up to a few $10 \%$ for squares writing where stress cumulates when writing lines array (as reported in the present paper). Finally, provided we remain within Type II regime, the "ultimate and key contribution" (i.e. final erasure of the nanopores) is always related to the viscosity(T) of the glass and the nanopores size (laser parameters dependent).

\section{Conclusions}

In this work, we discussed the different contributions of the total linear birefringence response in silica glass induced by femtosecond laser irradiation within nanogratings regime, as well as their corresponding erasure mechanism during a high temperature annealing process. The results of UV absorption spectra had revealed that point defects induce a minor effect to the nanogratings refractive indices $\mathrm{n}_{1}$ and $\mathrm{n}_{2}$ (and thus on the measured birefringence or retardance). Raman spectroscopy pointed out an increase of the glass density (likely induced by a High-Pressure High temperature mechanism) between the nanolayers and density has been estimated to be around 2.25-2.27 in agreement with a refractive index changes on the order of $+10^{-2}$.

The point defects centers are bleached under a fairly low temperature thermal treatment $\left(<600{ }^{\circ} \mathrm{C}\right)$ and no significant change in the retardance value can be found in this 


\section{WILEY-VCH}

temperature range. The subsequent unexpected rise from $600{ }^{\circ} \mathrm{C}-1000{ }^{\circ} \mathrm{C}$ is attributed to the co-existence of "Type I like" modifications with the ones specific of Type II i.e. nanogratings structuration with porous nanolayers. The progressive erasure of the former occurred at this stage and eventually caused an "abnormal" increase of the retardance R. Then, through monitoring the retardance $\mathrm{R}$ of the irradiated area and the surrounding stress-induced birefringence area during the annealing process, it is determined that stress relaxation is an important factor contributing to the measured birefringence. We note here that the compressive stress field produced by the nanoporous layers disappears before the annihilation of the nanopores themselves, likely by plastic deformation around the nanopores.

Finally, the porosity filling factor FF, which is determined by the SEM micrographs and then calculates the evolution of the pore size by the Rayleigh-Plesset (R-P) equation under a viscoelastic regime, is also found to play a key role in the ultimate thermal stability of the fs-laser induced nanogratings. This research is expected to provide a comprehensive view of the different mechanisms involved during thermal annealing of Type II modifications in glass, which can be valuable for reliable optical components lifetime adjustment for many applications including 5D optical data storage ${ }^{[10,11]}$ and sensing applications ${ }^{[20,23]}$ in harsh environment.

\section{Acknowledgements}

This research was funded by Agence Nationale pour la Recherche, FLAG/IR project, grant number ANR-18-CE08-0004-01, CNRS Défi Instrumentation aux Limites, UltraBragg project and International Emerging Actions (IEA) - INC 2020-2021.

\section{Conflicts of Interest}

The authors declare no conflict of interest.

Received: ((will be filled in by the editorial staff))

Revised: ((will be filled in by the editorial staff))

Published online: ((will be filled in by the editorial staff)) 


\section{Appendix A}

The form birefringence related to the so-called nanogratings is quantitatively correlated to the porosity-filling factor of these nanostructures has been demonstrated by our group recently. The Rayleigh-Plesset (R-P) equation was used to simulate the erasure of pores in the nanostructure during the annealing process, the equation describes the evolution of a spherical bubble inside an incompressible Newtonian fluid, and it can be expressed as follows:

$$
\frac{\Delta P}{\rho}=R_{\text {pore }} \frac{d^{2} R_{\text {pore }}}{d t^{2}}+\frac{3}{2}\left(\frac{d R_{\text {pore }}}{d t}\right)^{2}+\frac{4 \eta(T)}{\rho R_{\text {pore }}} \frac{d R_{\text {pore }}}{d t}+\frac{2 S}{\rho R_{\text {pore }}} .
$$

Here, $\Delta \mathrm{P}$ is the pressure difference (in $\mathrm{Pa}$ ) between the inside of the nanopore (supposed spherical) and far away from it, $\rho$ is the glass density (in $\mathrm{kg} \mathrm{m}^{-3}$ ), $\mathrm{R}_{\text {pore }}$ the radius (in $\mathrm{m}$ ) of the spherical nanopore, $t$ the time (in $s$ ), $\eta(T)$ the viscosity (in Pa.s), and $S$ is the surface energy (in $\mathrm{J} \mathrm{m}^{-2}$ ). The viscosity and its dependence with respect to temperature can be injected into the model by using a Vogel-Tammann-Fulcher (VTF) law in the form $\log (\eta)=\mathrm{A}+\mathrm{B} /\left(\mathrm{T}-\mathrm{T}_{0}\right)$. Initial conditions are $\mathrm{R}_{\text {pore }}($ at $\mathrm{t}=0)=\mathrm{R}_{0}$ and $\mathrm{dR}$ pore $/ \mathrm{dt}($ at $\mathrm{t}=0)=0$. The nanopore size diameter from the R-P equation needs to be converted into a normalized retardance $(\mathrm{R})$ value. The Maxwell-Garnet equation is first used to calculate the average refractive index of the porous nanolayer $\left(\mathrm{n}_{\mathrm{pl}}\right)$ :

$$
n_{p l}=\sqrt{n_{G}^{2} \frac{n_{G}^{2}+\frac{(1+2 F F)}{3}\left(n_{\text {pore }}^{2}-n_{G}^{2}\right)}{n_{G}^{2}+\frac{(1-F F)}{3}\left(n_{\text {pore }}^{2}-n_{G}^{2}\right)} .}
$$

$\mathrm{n}_{\mathrm{G}}$ is the fiber refractive index (taken as $\mathrm{n}_{\mathrm{G}}=1.484$, estimated from the chemical composition of the fiber), $\mathrm{n}_{\text {pore }}$ is the nanopore refractive index (taken equal to 1). Another important factor is the filling factor (FF) which is defined as the proportion of the nanopores' volume taken in a unit volume of porous nanolayer $(\mathrm{V})$, so it is obviously related to the number of nanopores $(\mathrm{N})$ with an averaged nanopore radius $\left(\mathrm{R}_{\text {pore }}\right)$ and can be calculated using:

$$
F F=N \frac{4 \pi R_{\text {pore }}^{3}}{3 V} .
$$

The birefringence $\mathrm{B}$ can be determined by the difference between the refractive indices of the ordinary axis $\left(n_{0}\right)$ and the extraordinary axis $\left(n_{e}\right)$. The following equation illustrates the detail:

$$
B=n_{o}-n_{e}=\sqrt{\left[1-\frac{\delta}{\Lambda}\right] n_{G}^{2}+\frac{\delta}{\Lambda} n_{p l}^{2}}-\left[\sqrt{\left.\frac{\left[1-\frac{\delta}{\Lambda}\right]}{n_{G}^{2}}+\frac{\frac{\delta}{\Lambda}}{n_{p l}^{2}}\right]^{-1}} .\right.
$$

$\mathrm{n}_{\mathrm{G}}$ represents the refractive index between the porous nanolayers, $\Lambda$ is the average spacing between nanolayers, $\delta$ is the porous nanolayer thickness, and $(\Lambda-\delta)$ is the interlayer thickness. With the birefringence $\mathrm{B}$ calculated, the retardance $\mathrm{R}$ can be worked out by the expression $\mathrm{R}=\mathrm{B} \times \mathrm{L}$, where $\mathrm{B}$ is the birefringence and $\mathrm{L}$ is the length of the birefringent object being measured. Finally, we take into account the same conditions for a direct comparison of the retardance evolution during annealing between experiment and simulation, 


\section{WILEY-VCH}

and to further explore the relationship between the form birefringence and the porosity-filling factor of the nanostructures.

\section{Appendix A2}

In ref fibers ${ }^{[45]}$, we find that if the erasure kinetics is Arrhenius type with distributed activation energy, and if this distribution is according to a sigmoidal derivative with the following expression:

$$
[B](t, T)=B_{0}\left(\frac{1}{1+\exp \left(-\frac{2 \ln (3) E_{0}}{\Delta_{E}}\right)\left(k_{0} t\right) \frac{2 \ln (3) k_{B} T}{\Delta_{E}}}\right) .
$$

$\mathrm{B}_{0}$ is just an initial value of the followed quantity (for example the optical retardance).

$\mathrm{k}_{\mathrm{B}}$ the Boltzmann constant: $8.617333262 \times 10-5, \mathrm{eV} \mathrm{K}^{-1}$

$\mathrm{k}_{0}$ the attempt to escape frequency in $\mathrm{s}^{-1}$

$\Delta_{\mathrm{E}}$ the FWHM of the activation energy distribution that can be rewritten as $\Delta_{E}=$ $k_{B} \Delta_{T}^{\delta t} \ln \left(k_{o} \delta t\right)$. Here $\Delta_{\mathrm{T}}$ is a $\mathrm{T}$ deviation of which corresponds to the fall of $[B](t, T)$ around $\mathrm{T}_{0}$ and $\delta \mathrm{t}$ being the isochronal annealing time.

"a" is a coefficient equals to $\exp \left(-2 \ln (3) E_{0} / \Delta_{E}\right)$ (where $\mathrm{E}_{0}$ is the center of the distribution. Thus it is worth to note that $\Delta_{\mathrm{E}}$ and $\mathrm{E}_{0}$ define the distribution.

Then we have $E_{0}=k_{B} T_{0} \ln \left(k_{o} \delta t\right)$ and $\mathrm{T}_{0}$ is this the inflection point of the falling curve (isochronal annealing), so $a=\exp \left(-2 \ln (3) T_{0} / \Delta_{T}^{\delta t}\right)$.

Finally, we can rewrite Eq. 1 as follows:

or $R_{\text {norm }}(t, T)=a\left(\frac{1}{1+(9) \frac{T-T_{0}}{\Delta t}}\right)$

$$
R_{\text {norm }}(t, T)=a\left(\frac{1}{1+\exp \left(-2 \ln (3) T_{0} / \Delta_{T}^{\delta t}\right)(3)^{\frac{2 T}{\Delta_{T} t}}}\right) .
$$




\section{Main References}

[1]. R. Taylor, C. Hnatovsky and E. Simova, Laser Photonics Rev. 2008, 2, 26-46.

[2]. D. Rayner, A. Naumov and P. Corkum, Opt. Express. 2005, 13, 3208-3217.

[3]. P. Kazansky, H. Inouye, T. Mitsuyu, K. Miura, J. Qiu, K. Hirao and F. Starrost, Rev. Lett. 1999, 82, 2199.

[4]. J. Qiu, P. Kazanski, J. Si, K. Miura, T. Mitsuyu, K. Hirao and A. L. Gaeta, Appl. phys. lett. 2000, 77, 1940-1942.

[5]. L. Sudrie, M. Franco, B. Prade and A. Mysyrowicz, Opt. Commun. 2001, 191, 333-339.

[6]. Y. Shimotsuma, P. G. Kazansky, J. Qiu and K. Hirao, Phy. Rev. Lett. 2003, 91, 247405.

[7]. M. Lancry, B. Poumellec, J. Canning, K. Cook, J. C. Poulin and F. Brisset, Laser Photonics Rev. 2013, 7, 953-962.

[8]. M. Lancry, B. Poumellec, A. Chahid-Erraji, M. Beresna and P. Kazansky, Opt. Mater. Express. 2011, 1, 711-723.

[9]. G. C. Kahandawa, J. Epaarachchi, H. Wang and K. Lau, Photonic Sens. 2012, 2, 203-214. [10]. J. Zhang, M. Gecevičius, M. Beresna and P. G. Kazansky, Phy. Rev. Lett. 2014, 112, 033901.

[11]. Y. Shimotsuma, M. Sakakura, P. G. Kazansky, M. Beresna, J. Qiu, K. Miura and K. Hirao, Adv. Mater. 2010, 22, 4039-4043.

[12]. E. Bricchi and P. G. Kazansky, Appl. phys. lett. 2006, 88, 111119.

[13]. S. Richter, M. Heinrich, S. Döring, A. Tünnermann, S. Nolte and U. Peschel, J. Laser Appl. 2012, 24, 042008.

[14]. J. J. Witcher, W. J. Reichman, L. B. Fletcher, N. W. Troy and D. M. Krol, Opt. Mater. Express. 2013, 3, 502-510.

[15]. F. Zhang, Y. Yu, C. Cheng, Y. Dai, H. Zhang and J. Qiu, Appl. Phys. B. 2014, 117, 5358.

[16]. S.-E. Wei, Y. Wang, H. Yao, M. Cavillon, B. Poumellec, G.-D. Peng and M. Lancry, Sensors. 2020, 20, 762 .

[17]. Y. Wang, S. Wei, M. R. Cicconi, Y. Tsuji, M. Shimizu, Y. Shimotsuma, K. Miura, G. D. Peng, D. R. Neuville and B. Poumellec, J. Am. Ceram. Soc. 2020, 8, 4286-4294.

[18]. M. Gecevičius, University of Southampton, 2015.

[19]. T. Asai, Y. Shimotsuma, T. Kurita, A. Murata, S. Kubota, M. Sakakura, K. Miura, F. Brisset, B. Poumellec and M. Lancry, J. Am. Ceram. Soc. 2015, 98, 1471-1477.

[20]. D. Grobnic, C. Hnatovsky, S. Dedyulin, R. B. Walker, H. Ding and S. J. Mihailov, Sensors. 2021, 21, 1454. 


\section{WILEY-VCH}

[21]. M. Cavillon, M. Lancry, B. Poumellec, Y. Wang, J. Canning, K. Cook, T. Hawkins, P. Dragic and J. Ballato, Journal of Physics: Photonics. 2019, 1, 042001.

[22]. C. W. Smelser, S. J. Mihailov and D. Grobnic, Opt. Express. 2005, 13, 5377-5386.

[23]. S. J. Mihailov, D. Grobnic, C. Hnatovsky, R. B. Walker, P. Lu, D. Coulas and H. Ding, Sensors. 2017, 17, 2909.

[24]. D. Grobnic, C. Hnatovsky and S. J. Mihailov, Opt. Express. 2016, 24, 28704-28712.

[25]. D. Grobnic, C. W. Smelser, S. J. Mihailov and R. B. Walker, Meas. Sci. Technol. 2006, $17,1009$.

[26]. Y. Li, C. Liao, D. Wang, T. Sun and K. T. Grattan, Opt. Express. 2008, 16, 2123921247.

[27]. C. Hnatovsky, D. Grobnic and S. J. Mihailov, Opt. Express. 2018, 26, 23550-23564.

[28]. Y. Li, M. Yang, D. Wang, J. Lu, T. Sun and K. T. Grattan, Opt. Express. 2009, 17, 19785-19790.

[29]. Y. Li, M. Yang, C. Liao, D. Wang, J. Lu and P. Lu, J. Lightwave Technol. 2011, 29, 1555-1559.

[30]. R. Brueckner, J. Non-Cryst. Solids. 1970, 5, 123-175.

[31]. R. Desmarchelier, B. Poumellec, F. Brisset, S. Mazerat and M. Lancry, World J. Nano Sci. Eng. 2015, 5, 115.

[32]. B. McMillen, C. Athanasiou and Y. Bellouard, Opt. Express. 2016, 24, 27239-27252.

[33]. J. Tian, H. Yao, M. Cavillon, E. Garcia-Caurel, R. Ossikovski, M. Stchakovsky, C. Eypert, B. Poumellec and M. Lancry, Micromachines. 2020, 11, 131.

[34]. J. D. Musgraves, J. Hu and L. Calvez, Springer Handbook of Glass, Springer Nature, 2019.

[35]. M. Cavillon, Y. Wang, B. Poumellec, F. Brisset and M. Lancry, Appl. Phys. A, 2020, $126,1-9$.

[36]. F. Messina and M. Cannas, J. Non-Cryst. Solids. 2007, 353, 522-525.

[37]. M. Beresna, M. Gecevičius, M. Lancry, B. Poumellec and P. Kazansky, Appl. phys. lett. 2013, 103, 131903.

[38]. P. Yeh, Opt. Commun. 1978, 26, 289-292.

[39]. N. Ollier, M. Lancry, C. Martinet, V. Martinez, S. Le Floch and D. Neuville, Sci. rep. 2019, 9, 1-8.

[40]. J. W. Chan, T. Huser, S. Risbud and D. Krol, Opt. lett. 2001, 26, 1726-1728.

[41]. F. Zimmermann, Diss. 2017.

[42]. I. Reghioua, M. Lancry, O. Cavani, S. L. Floch, D. R. Neuville and N. Ollier, Appl. phys. lett. 2019, 115, 251101.

[43]. P. Vlugter, E. Block and Y. Bellouard, Phys. Rev. Mater. 2019, 3, 053802.

[44]. Y. Bellouard, A. Champion, B. McMillen, S. Mukherjee, R. R. Thomson, C. Pépin, P. Gillet and Y. Cheng, Optica. 2016, 3, 1285-1293.

[45]. B. Poumellec and M. Lancry, Fibers. 2015, 3, 206-252.

[46]. M. Sakakura, Y. Lei, L. Wang, Y.-H. Yu and P. G. Kazansky, Light-Sci. Appl. 2020, 9, $1-10$.

[47]. A. Champion, M. Beresna, P. Kazansky and Y. Bellouard, Opt. Express. 2013, 21, 24942-24951.

[48]. R. Oldenbourg, E. Salmon and P. Tran, Biophys. J. 1998, 74, 645-654. 


\section{WILEY-VCH}

[49]. W. L. Bragg and A. B. Pippard, Acta Crystallogr. 1953, 6, 865-867.

[50]. E. Bricchi, B. G. Klappauf and P. G. Kazansky, Opt. lett. 2004, 29, 119-121.

[51]. V. Bhardwaj, P. Corkum, D. Rayner, C. Hnatovsky, E. Simova and R. Taylor, Opt. lett. 2004, 29, 1312-1314.

[52]. F. Dürr, H. Limberger, R. Salathe, F. Hindle, M. Douay, E. Fertein and C. Przygodzki, Appl. phys. lett. 2004, 84, 4983-4985.

[53]. B. Poumellec, L. Sudrie, M. Franco, B. Prade and A. Mysyrowicz, Opt. Express. 2003, 11, 1070-1079.

[54]. A. Champion and Y. Bellouard, Opt. Mater. Express. 2012, 2, 789-798.

[55]. J. Canning, M. Lancry, K. Cook, A. Weickman, F. Brisset and B. Poumellec, Opt. Mater. Express. 2011, 1, 998-1008.

[56]. L. Yuan, B. Cheng, J. Huang, J. Liu, H. Wang, X. Lan and H. Xiao, Opt. Express. 2016, 24, 1062-1071.

[57]. L. A. Fernandes, J. R. Grenier, P. R. Herman, J. S. Aitchison and P. V. Marques, Opt. Express. 2012, 20, 24103-24114.

[58]. L. A. Fernandes, J. R. Grenier, P. V. Marques, J. S. Aitchison and P. R. Herman, J. Lightwave Technol. 2013, 31, 3563-3569.

[59]. Y. Bellouard, E. Barthel, A. Said, M. Dugan and P. Bado, Opt. Express. 2008, 16, 19520-19534.

[60]. B. Poumellec, M. Lancry, A. Chahid-Erraji and P. G. Kazansky, Opt. Mater. Express. 2011, 1, 766-782.

[61]. Y. Wang, S. Wei, M. Cavillon, B. Sapaly, B. Poumellec, G.-D. Peng, J. Canning and M. Lancry, Appl. Sci. 2021, 11, 600.

[62]. M. Lancry, international conference on laser ablation. 2017. 


\section{Secondary Reference}

1]. R. Taylor, C. Hnatovsky and E. Simova, Laser \& Photonics Reviews, 2008, 2, 26-46.

2]. D. Rayner, A. Naumov and P. Corkum, Optics express, 2005, 13, 3208-3217.

3]. P. Kazansky, H. Inouye, T. Mitsuyu, K. Miura, J. Qiu, K. Hirao and F. Starrost, Physical Review Letters, 1999, 82, 2199.

4]. J. Qiu, P. Kazanski, J. Si, K. Miura, T. Mitsuyu, K. Hirao and A. L. Gaeta, Applied Physics Letters, 2000, 77, 1940-1942.

5]. L. Sudrie, M. Franco, B. Prade and A. Mysyrowicz, Optics Communications, 2001, 191, 333-339.

6]. Y. Shimotsuma, P. G. Kazansky, J. Qiu and K. Hirao, Physical review letters, 2003, 91, 247405.

7]. M. Lancry, B. Poumellec, J. Canning, K. Cook, J. C. Poulin and F. Brisset, Laser \& Photonics Reviews, 2013, 7, 953-962.

8]. M. Lancry, B. Poumellec, A. Chahid-Erraji, M. Beresna and P. Kazansky, Optical Materials Express, 2011, 1, 711-723.

9]. G. C. Kahandawa, J. Epaarachchi, H. Wang and K. Lau, Photonic Sensors, 2012, 2, 203-214.

10]. J. Zhang, M. Gecevičius, M. Beresna and P. G. Kazansky, Physical review letters, 2014, 112, 033901.

11]. Y. Shimotsuma, M. Sakakura, P. G. Kazansky, M. Beresna, J. Qiu, K. Miura and K. Hirao, Advanced materials, 2010, 22, 4039-4043.

12]. E. Bricchi and P. G. Kazansky, Applied physics letters, 2006, 88, 111119.

13]. S. Richter, M. Heinrich, S. Döring, A. Tünnermann, S. Nolte and U. Peschel, Journal of Laser Applications, 2012, 24, 042008.

14]. J. J. Witcher, W. J. Reichman, L. B. Fletcher, N. W. Troy and D. M. Krol, Optical Materials Express, 2013, 3, 502-510.

15]. F. Zhang, Y. Yu, C. Cheng, Y. Dai, H. Zhang and J. Qiu, Applied Physics B, 2014, 117, 53-58.

16]. S.-E. Wei, Y. Wang, H. Yao, M. Cavillon, B. Poumellec, G.-D. Peng and M. Lancry, Sensors, 2020, 20, 762.

17]. Y. Wang, S. Wei, M. R. Cicconi, Y. Tsuji, M. Shimizu, Y. Shimotsuma, K. Miura, G. D. Peng, D. R. Neuville and B. Poumellec, Journal of the American Ceramic Society, 2020.

18]. M. Gecevičius, University of Southampton, 2015.

19]. T. Asai, Y. Shimotsuma, T. Kurita, A. Murata, S. Kubota, M. Sakakura, K. Miura, F. Brisset, B. Poumellec and M. Lancry, Journal of the American Ceramic Society, 2015, 98, 1471-1477. 


\section{WILEY-VCH}

20]. D. Grobnic, C. Hnatovsky, S. Dedyulin, R. B. Walker, H. Ding and S. J. Mihailov, Sensors, 2021, 21, 1454.

21]. M. Cavillon, M. Lancry, B. Poumellec, Y. Wang, J. Canning, K. Cook, T. Hawkins, P. Dragic and J. Ballato, Journal of Physics: Photonics, 2019, 1, 042001.

22]. C. W. Smelser, S. J. Mihailov and D. Grobnic, Optics express, 2005, 13, 5377-5386.

23]. S. J. Mihailov, D. Grobnic, C. Hnatovsky, R. B. Walker, P. Lu, D. Coulas and H. Ding, Sensors, 2017, 17, 2909.

24]. D. Grobnic, C. Hnatovsky and S. J. Mihailov, Optics express, 2016, 24, 28704-28712.

25]. D. Grobnic, C. W. Smelser, S. J. Mihailov and R. B. Walker, Measurement Science and Technology, 2006, 17, 1009.

26]. Y. Li, C. Liao, D. Wang, T. Sun and K. T. Grattan, Optics express, 2008, 16, 2123921247.

27]. C. Hnatovsky, D. Grobnic and S. J. Mihailov, Optics express, 2018, 26, 23550-23564.

28]. Y. Li, M. Yang, D. Wang, J. Lu, T. Sun and K. T. Grattan, Optics express, 2009, 17, 19785-19790.

29]. Y. Li, M. Yang, C. Liao, D. Wang, J. Lu and P. Lu, Journal of Lightwave Technology, 2011, 29, 1555-1559.

30]. R. Brueckner, Journal of non-crystalline solids, 1970, 5, 123-175.

31]. R. Desmarchelier, B. Poumellec, F. Brisset, S. Mazerat and M. Lancry, World Journal of Nano Science and Engineering, 2015, 5, 115.

32]. B. McMillen, C. Athanasiou and Y. Bellouard, Optics Express, 2016, 24, 2723927252.

33]. J. Tian, H. Yao, M. Cavillon, E. Garcia-Caurel, R. Ossikovski, M. Stchakovsky, C. Eypert, B. Poumellec and M. Lancry, Micromachines, 2020, 11, 131.

34]. J. D. Musgraves, J. Hu and L. Calvez, Springer Handbook of Glass, Springer Nature, 2019.

35]. M. Cavillon, Y. Wang, B. Poumellec, F. Brisset and M. Lancry, Applied Physics A, 2020, 126, 1-9.

36]. F. Messina and M. Cannas, Journal of non-crystalline solids, 2007, 353, 522-525.

37]. M. Beresna, M. Gecevičius, M. Lancry, B. Poumellec and P. Kazansky, Applied Physics Letters, 2013, 103, 131903.

38]. P. Yeh, Optics Communications, 1978, 26, 289-292.

39]. N. Ollier, M. Lancry, C. Martinet, V. Martinez, S. Le Floch and D. Neuville, Scientific reports, 2019, 9, 1-8.

40]. J. W. Chan, T. Huser, S. Risbud and D. Krol, Optics letters, 2001, 26, 1726-1728.

41]. F. Zimmermann, 2017.

42]. I. Reghioua, M. Lancry, O. Cavani, S. L. Floch, D. R. Neuville and N. Ollier, Applied Physics Letters, 2019, 115, 251101.

43]. P. Vlugter, E. Block and Y. Bellouard, Physical Review Materials, 2019, 3, 053802.

44]. Y. Bellouard, A. Champion, B. McMillen, S. Mukherjee, R. R. Thomson, C. Pépin, P. Gillet and Y. Cheng, Optica, 2016, 3, 1285-1293.

45]. B. Poumellec and M. Lancry, Fibers, 2015, 3, 206-252.

46]. M. Sakakura, Y. Lei, L. Wang, Y.-H. Yu and P. G. Kazansky, Light: Science \& Applications, 2020, 9, 1-10.

47]. A. Champion, M. Beresna, P. Kazansky and Y. Bellouard, Optics express, 2013, 21, 24942-24951.

48]. R. Oldenbourg, E. Salmon and P. Tran, Biophysical journal, 1998, 74, 645-654.

49]. W. L. Bragg and A. B. Pippard, Acta Crystallographica, 1953, 6, 865-867.

50]. E. Bricchi, B. G. Klappauf and P. G. Kazansky, Optics letters, 2004, 29, 119-121.

51]. V. Bhardwaj, P. Corkum, D. Rayner, C. Hnatovsky, E. Simova and R. Taylor, Optics letters, 2004, 29, 1312-1314. 


\section{WILEY-VCH}

52]. F. Dürr, H. Limberger, R. Salathe, F. Hindle, M. Douay, E. Fertein and C. Przygodzki, Applied physics letters, 2004, 84, 4983-4985.

53]. B. Poumellec, L. Sudrie, M. Franco, B. Prade and A. Mysyrowicz, Optics Express, 2003, 11, 1070-1079.

54]. A. Champion and Y. Bellouard, Optical Materials Express, 2012, 2, 789-798.

55]. J. Canning, M. Lancry, K. Cook, A. Weickman, F. Brisset and B. Poumellec, Optical Materials Express, 2011, 1, 998-1008.

56]. L. Yuan, B. Cheng, J. Huang, J. Liu, H. Wang, X. Lan and H. Xiao, Optics Express, 2016, 24, 1062-1071.

57]. L. A. Fernandes, J. R. Grenier, P. R. Herman, J. S. Aitchison and P. V. Marques, Optics express, 2012, 20, 24103-24114.

58]. L. A. Fernandes, J. R. Grenier, P. V. Marques, J. S. Aitchison and P. R. Herman, Journal of lightwave technology, 2013, 31, 3563-3569.

59]. Y. Bellouard, E. Barthel, A. Said, M. Dugan and P. Bado, Optics Express, 2008, 16, 19520-19534.

60]. B. Poumellec, M. Lancry, A. Chahid-Erraji and P. G. Kazansky, Optical Materials Express, 2011, 1, 766-782.

61]. Y. Wang, S. Wei, M. Cavillon, B. Sapaly, B. Poumellec, G.-D. Peng, J. Canning and M. Lancry, Applied Sciences, 2021, 11, 600.

62]. M. Lancry, international conference on laser ablation, 2017. 